\title{
The myocardial infarct-exacerbating effect of cell-free DNA is mediated by the high-mobility group box 1-receptor for advanced glycation end products-Toll-like receptor 9 pathway
}

Yikui Tian, MD, ${ }^{\mathrm{a}, \mathrm{b}}$ Eric J. Charles, MD, ${ }^{\mathrm{a}}$ Zhen Yan, MD, ${ }^{\mathrm{c}}$ Di Wu, MS, ${ }^{\mathrm{a}}$ Brent A. French, PhD, ${ }^{\mathrm{c}, \mathrm{d}}$

Irving L. Kron, MD, and Zequan Yang, MD $^{\mathrm{a}, \mathrm{d}}$

\section{ABSTRACT}

Introduction: Damage-associated molecular patterns, such as high-mobility group box 1 (HMGB1) and cell-free DNA (cfDNA), play critical roles in mediating ischemia-reperfusion injury (IRI). HMGB1 activates RAGE to exacerbate IRI, but the mechanism underlying cfDNA-induced myocardial IRI remains unknown. We hypothesized that the infarct-exacerbating effect of cfDNA is mediated by HMGB1 and receptor for advanced glycation end products (RAGE).

Methods: C57BL/6 wild type mice, RAGE knockout (KO), and Toll-like receptor $9 \mathrm{KO}$ mice underwent 20- or 40-minute occlusions of the left coronary artery followed by up to 60 minutes of reperfusion. Cardiac coronary perfusate was acquired from ischemic hearts without reperfusion. Exogenous mitochondrial DNA was acquired from livers of normal C57BL/6 mice. Myocardial infarct size (IS) was reported as percent risk region, as measured by 2,3,5-triphenyltetrazolium chloride and Phthalo blue (Heucotech, Fairless Hill, $\mathrm{Pa}$ ) staining. cfDNA levels were measured by Sytox Green assay (Thermo Fisher Scientific, Waltham, Mass) and/or spectrophotometer.

Results: Free HMGB1 and cfDNA levels were increased in the ischemic myocardium during prolonged ischemia and subsequently in the plasma during reperfusion. In C57BL/6 mice undergoing $40^{\prime} / 60^{\prime}$ IRI, deoxyribonuclease I, or anti-HMGB1 monoclonal antibody reduced IS by approximately half to $29.0 \% \pm 5.2 \%$ and $24.3 \% \pm 3.5 \%(P<.05$ vs control $54.3 \% \pm 3.4 \%)$. However, combined treatment with deoxyribonuclease I + anti-HMGB1 monoclonal antibody did not further attenuate IS $(29.3 \% \pm 4.9 \%)$. In C57BL/6 mice undergoing $20^{\prime} / 60^{\prime}$ IRI, injection of $40^{\prime} / 5^{\prime}$ plasma upon reperfusion increased IS by more than 3 -fold (to $19.9 \pm 4.3 ; P<.05$ ). This IS exacerbation was abolished by pretreating the plasma with deoxyribonuclease I or by depleting the HMGB1 by immunoprecipitation, or by splenectomy. The infarct-exacerbating effect also disappeared in RAGE KO mice and Toll-like receptor $9 \mathrm{KO}$ mice. Injection of $40^{\prime} / 0^{\prime}$ coronary perfusate upon reperfusion similarly increased IS. The levels of HMGB1 and cfDNA were significantly elevated in the $40^{\prime} / 0^{\prime}$ coronary perfusate and $40^{\prime} /$ reperfusion $(\mathrm{min})$ plasma but not in those with $10^{\prime}$ ischemia. In C57BL/6 mice without IRI, $40^{\prime} / 5^{\prime}$ plasma significantly increased the interleukin- $1 \beta$ protein and messenger RNA expression in the spleen by

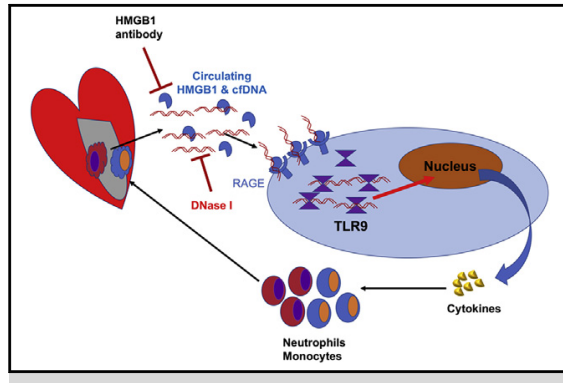

Schematic mechanism of the HMGB1-cfDNA complex in acute myocardial ischemia/reperfusion injury.

\section{Central Message}

HMGB1 and cfDNA are released from the heart upon reperfusion after ischemia and contribute importantly and interdependently to the reperfusion injury by a common RAGE-TLR9-dependent mechanism.

\section{Perspective}

HMGB1 and cfDNA are released from infarcted myocardium into the bloodstream during reperfusion and mediate inflammatory response and exacerbate infarct size via activating splenic RAGE-TLR9 pathway. Depletion of either HMGB1 or cfDNA upon reperfusion suffices to abrogate the reperfusion injury. These results will help to develop novel therapeutical strategies to reduce myocardial reperfusion injury.

See Commentaries on pages 2270 and 2272.
From the Departments of ${ }^{\text {a Surgery, }}{ }^{\mathrm{c}}$ Cardiovascular Medicine, and ${ }^{\mathrm{d}}$ Biomedical Engineering, University of Virginia, Charlottesville, Va; and Department of ${ }^{\mathrm{b}}$ Cardiovascular Surgery, Tianjin Medical University General Hospital, Tianjin, China.

This study was funded in part by National Institutes of Health grant No. R01 HL130082 to Dr Yang, and a National Natural Science Foundation of China grant (No. 81400213) to Dr Tian.

Received for publication May 5, 2018; revisions received Aug 13, 2018; accepted for publication Sept 12, 2018; available ahead of print Nov 3, 2018.

\footnotetext{
Address for reprints: Zequan Yang, MD, Department of Surgery, University of Virginia, 419 Lane Rd, MR4 Bldg, Rm 3119, Charlottesville, VA 22908 (E-mail: zy6b@virginia.edu). 0022-5223

Copyright (C) 2018 by The American Association for Thoracic Surgery. Published by Elsevier Inc. This is an open access article under the CC BY-NC-ND license (http:// creativecommons.org/licenses/by-nc-nd/4.0/).

https://doi.org/10.1016/j.jtcvs.2018.09.043
} 

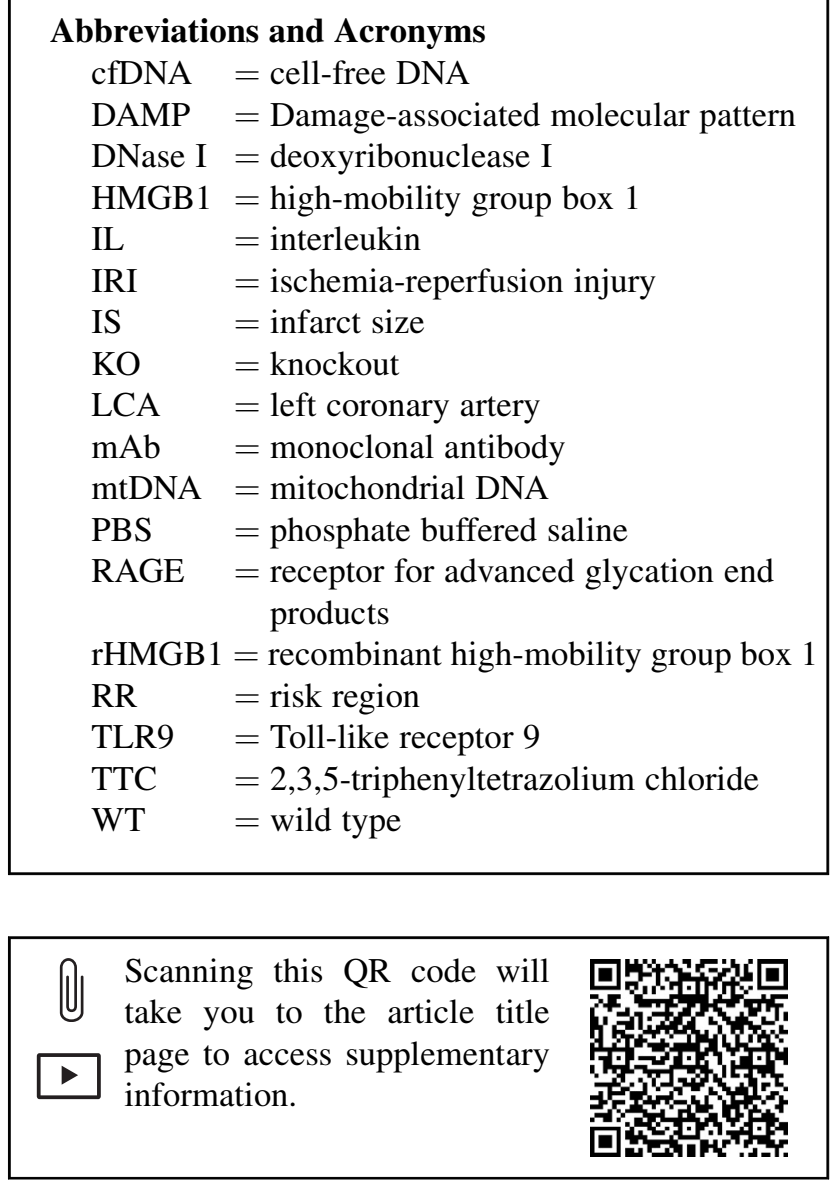

30 minutes after injection. Intravenous bolus injection of recombinant HMGB1 $(0.1 \mu \mathrm{g} / \mathrm{g})$ or mitochondrial DNA $(0.5 \mu \mathrm{g} / \mathrm{g}) 5$ minutes before reperfusion did not exacerbate IS $(P=$ not significant vs control). However, combined administration of recombinant HMGB1 + mitochondrial DNA significantly increased IS $(P<.05$ vs individual treated groups) and this infarct-exacerbating effect disappeared in RAGE KO mice and splenectomized C57BL/6 mice. The accumulation of cfDNA in the spleen after combined recombinant HMGB1 + mitochondrial DNA treatment was significantly more elevated in C57BL/6 mice than in RAGE KO mice.

Conclusions: Both HMGB1 and cfDNA are released from the heart upon reperfusion after prolonged ischemia and both contribute importantly and interdependently to post-IRI by a common RAGE-Toll-like receptor 9-dependent mechanism. Depleting either of these 2 damage-associated molecular patterns suffices to significantly reduce IS by approximately $50 \%$. (J Thorac Cardiovasc Surg 2019;157:2256-69)
Cell-free DNA (cfDNA) is increased in a variety of diseases, including myocardial infarction and contributes to inflammatory responses. Necrotic cardiomyocytes release DNA, predominantly mitochondrial DNA (mtDNA), that contribute to myocardial ischemia-reperfusion injury (IRI) ${ }^{1-3}$ It has been reported that circulating DNA plays important roles in mediating inflammatory responses and inducing myocardial IRI. ${ }^{4}$ Blocking either high-mobility group box 1 (HMGB1) or cfDNA suffices to protect the heart against myocardial IRI. ${ }^{1,5,6}$ Prolonged ischemia results in myocardial necrosis, and our recent studies demonstrate that necrotic cardiomyocytes release HMGB1 into the bloodstream during reperfusion to activate splenic leukocytes via receptor for advanced glycation end products (RAGE). The activated splenic leukocytes then invade the heart to exacerbate myocardial infarct size. $^{7}$ However, the relationship between HMGB1 and cfDNA in exacerbating myocardial IRI remains to be elucidated.

The aim of current study was to define the role of ischemic cardiomyocyte-released cfDNA in exacerbating myocardial infarct size during reperfusion. Furthermore, the collective effect of HMGB1 and cfDNA in mediating IRI was investigated. We hypothesized that upon reperfusion, both HMGB1 and cfDNA are flushed out of necrotic cardiomyocytes and into the bloodstream, where they function as damage-associated molecular patterns (DAMPs), not only to promote systemic inflammatory responses in general, but also more specifically to activate the splenic leukocytes responsible for exacerbating myocardial IRI and ultimately infarct size.

\section{METHODS}

This study conformed to the Guide for the Care and Use of Laboratory Animals published by the National Institutes of Health and was conducted under protocols approved by the University of Virginia's Institutional Animal Care and Use Committee.

\section{AGENTS}

Sodium pentobarbital, deoxyribonuclease I (DNase I) and 2,3,5-triphenyltetrazolium chloride (TTC) were purchased from Sigma-Aldrich (St Louis, Mo). Sytox green and mouse recombinant HMGB1 from Thermo Fisher Scientific (Waltham, Mass), anti-HMGB1 monoclonal antibody ( $\mathrm{mAb}$ ) from Abcam (Cambridge, Mass), and IL-1 $\beta$ mAb from BD Biosciences (San Jose, Calif).

\section{Animals and Experimental Protocols}

C57BL/6 wild type (WT) mice and Toll-like receptor 9 (TLR9) knockout (KO) (aged 9-11 wk, purchased from The Jackson Laboratory, Bar Harbor, Me) and RAGE KO mice $^{8}$ were randomly assigned to either IRI groups or sham surgery group. RAGE KO mice were backcrossed onto 
C57BL/6 for 10 generations and thus were congenic with C57BL/6.

\section{Splenectomy}

As described previously, ${ }^{9} 10$ mice were anesthetized with sodium pentobarbital $(80 \mathrm{mg} / \mathrm{kg}$ intraperitoneal) and orally intubated. Artificial respiration was maintained with an inspired oxygen fraction of $0.80,120$ strokes per minute, and a stroke volume at $1.0 \mu \mathrm{L} / \mathrm{g}$ weight. A small midline abdominal incision was made and the peritoneal cavity entered. The spleen was located and brought to the incision. The hilum was clamped and ligated with 3-0 silk and the spleen excised. The incision was closed in 2 layers using 5-0 prolene sutures. The mice then underwent further procedures as described below.

\section{Myocardial IRI and Measurement of Infarct Size}

In previous work, we established that myocardial infarct size (IS) as measured by late-gadolinium enhanced magnetic resonance imaging at 60 minutes of reperfusion attains $95 \%$ of the size measured by the same method at 24 hours postreperfusion in mice. ${ }^{9,11}$ We therefore used 60 minutes of reperfusion in the present study. The left coronary artery (LCA) of WT, TLR9 KO, and RAGE KO mice was ligated for durations of 10,20 , or 40 minutes to impose graded levels of ischemia followed by 0 or up to 60 minutes of reperfusion as detailed previously. ${ }^{11-14}$ The duration of ischemia/reperfusion is denoted as "minutes ${ }^{(')}$ /minutes (')." Briefly, mice were anesthetized with sodium pentobarbital $(80 \mathrm{mg} / \mathrm{kg}$ intraperitoneal $)$ and orally intubated. The heart was exposed through a left thoracotomy. The LCA was identified under a dissecting microscope. An 8-0 prolene suture was placed around the LCA at a level $1 \mathrm{~mm}$ inferior to the left auricle. Ischemia was induced by securing a suture over a piece of PE-60 tubing (Becton Dickison and Company, Sparks, Md) placed parallel to the LCA, and reperfusion was achieved by removing the tube. Successful ligation of the LCA was confirmed by blanching in the ischemic zone, with color change from pink to gray (Video 1). For the study of infarct size, mice were killed 60 minutes after reperfusion, and explanted hearts were cannulated through the ascending aorta for perfusion with $3 \mathrm{~mL}$ of $1.0 \%$ TTC. The LCA was then reoccluded with the same suture used for coronary occlusion before $10 \%$ Phthalo blue (Heucotech, Fairless Hill, Pa) perfusion to determine risk region (RR). The left ventricle was then cut into 5 to 7 transverse slices that were weighed and digitally photographed to determine IS as $\%$ RR. $^{12,13}$

\section{Preparation of Cardiac Coronary Perfusate}

C57BL/6 WT mice underwent either 10 minutes or 40 minutes of LCA occlusion. At the end of the index ischemia without initiation of reperfusion, the blood was

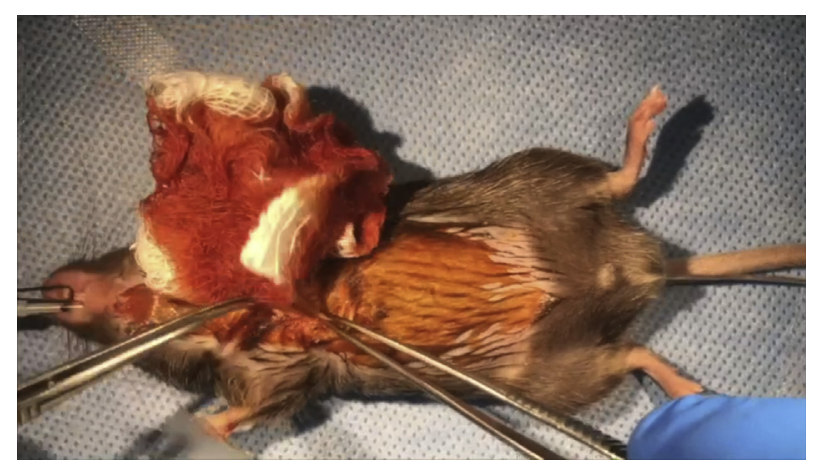

VIDEO 1. Surgical procedure to induce myocardial ischemia/reperfusion injury in mouse. Video available at: https://www.jtcvs.org/article/S00225223(18)32547-9/fulltext.

acquired and the heart was harvested. The explanted hearts were cannulated through the ascending aorta for perfusion with $500 \mu \mathrm{L}$ phosphate buffered saline (PBS) at $37^{\circ} \mathrm{C}$. This same perfusate was used again to perfuse the heart 4 times before final collection of the perfusate (up to $300 \mu \mathrm{L}$, during 1 minute) for use in the recipient mice. Cardiac coronary perfusate was administered 5 minutes before reperfusion as an intravenous bolus at a dose of $2 \mu \mathrm{L} / \mathrm{g}$ recipient mouse body weight.

\section{Preparation of mtDNA}

Extraction of mtDNA. The mtDNA was generated from the livers of normal mice (mtDNA donor) and from the hearts of mice subjected to IRI. Mitochondria were isolated from livers or hearts using the Mitochondria Isolation Kit for Tissue (Thermo Fisher Scientific) according to the manufacturer's protocol. DNA was immediately isolated from mitochondria using the DNeasy Blood and Tissue Kit (Qiagen, Santa Clarita, Calif). Eluted DNA was immediately sonicated 10 times with a Vibra-Cell sonicator (Sonics and Materials, Newtown, Conn), each sonication lasting 30 seconds and separated from the next by a 30 -second sonication-free interval, to produce mtDNA fragments of 50 to 150 base pairs. Aliquots were stored at $-20^{\circ} \mathrm{C}$.

mtDNA quantification. The mtDNA extracted from livers and hearts were quantitatively measured using a Nanodrop 2000 Spectrophotometer (Thermo Fisher Scientific).

\section{Western Blot Analysis}

HMGB1 levels in cardiac perfusate and plasma were assessed by Western blot analysis as previous described. ${ }^{14}$ Briefly, cardiac perfusate and blood samples were obtained and centrifuged at $1600 \mathrm{~g}$ for 20 minutes. Total protein concentrations were determined by BCA Protein Assay Kit (Thermo Fisher Scientific). Twenty micrograms of protein were separated by $10 \%$ sodium dodecyl sulfate polyacrylamide gel electrophoresis. After transfer, nitrocellulose membranes (Bio-Rad, Hercules, Calif) were probed with primary antibodies against HMGB1 (Abcam) 
at a 1:2000 dilution and secondary antibodies (Promega, Madison, Wis) at a 1:5000 dilution in blocking solution $(0.5 \%$ bovine serum albumin in tris-buffered saline with Tween). Proteins were visualized with enhanced chemiluminescent substrate (Thermo Fisher Scientific) followed by densitometry using a Fluorchem 8900 imaging system (Alpha Innotech, Santa Clara, Calif).

\section{Immunoprecipitation of HMGB1}

Depletion of HMGB1 in plasma was achieved by immunoprecipitation with a Dynabeads Protein A Immunoprecipitation Kit (Life Technologies, Grand Island, NY) according to the manufacturer's instructions. ${ }^{7}$ Briefly, the HMGB 1 antibody (10 $\mu \mathrm{g}$ in $200 \mu \mathrm{L}$ binding buffer) was preincubated with Dynabeads Protein A for 15 minutes at room temperature. Then, $100 \mu \mathrm{L} 40^{\prime} / 5^{\prime}$ plasma was mixed with the Dynabeads for 1 hour at room temperature, and the supernatant was collected for use. Western blot analysis was used to confirm efficient HMGB1 depletion. Rabbit immunoglobulin $\mathrm{G}$ was used as a negative control for this analysis.

\section{Enzyme-Linked Immunosorbant Assay of Interleukin-1 $\beta$ in the Plasma and Splenic Tissue}

Levels of interleukin (IL)-1 $\beta$ protein present in splenic tissue homogenates and plasma samples were measured using IL- $1 \beta$ Mouse ELISA Kit (Thermo Fisher Scientific) according to manufacturer's protocol.

\section{Measurement of Tissue and Plasma cfDNA by Sytox Green}

Sytox Green binds nucleic acids with minimal base selectivity. It does not cross intact membranes. It exhibits a $>500$-fold fluorescence enhancement upon binding nucleic acids, with an emission peak of $523 \mathrm{~nm}$ when excited by a 450 to $490 \mathrm{~nm}$.

Evaluation of plasma or perfusate cfDNA by ex vivo Sytox Green administration. Fifty microliters of plasma (1:5 diluted) or coronary perfusate (1:5 diluted) were mixed with $50 \mu \mathrm{L} 2 \mu \mathrm{M}$ Sytox Green dye in a 96-well plate. After incubation at $37^{\circ} \mathrm{C}$ for 60 minutes, the plate was scanned on a fluorescence microplate reader (SpectraMax Gemini XS; Molecular Devices, Sunnyvale, Calif).

Evaluation of tissue cfDNA by in vivo Sytox Green administration. Sytox Green dye was injected intravenously at a bolus dose of $50 \mu \mathrm{L} 1$-mM Sytox Green 1 minute before reperfusion. The heart was harvested 30 minutes after injection in sham mice, and 5 minutes, 15 minutes, or 30 minutes following reperfusion in ischemic mice. The left ventricle was cut into anterior wall (ischemic) and posterior wall (nonischemic) sections. The LV sections were then imaged using an IVIS Lumina Imaging System (PerkinElmer, Akron, Ohio) at the appropriate wavelength. The left ventricle sections were then homogenized in PBS buffer and centrifuged at $14,000 \mathrm{rpm}$ at $4{ }^{\circ} \mathrm{C}$ for 10 minutes. The protein contents of the homogenates were determined, and they were diluted as appropriate (approximately 1:50) in PBS to normalize protein content between samples. The dilutions were then loaded onto a 96-well plate and fluorescence at $523 \mathrm{~nm}$ was measured using a fluorescence microplate reader.

\section{Measurement of DNA in Tissues Using Spectrophotometer}

mtDNA was extracted from the heart tissue and total cytosolic DNA was extracted from the spleen. The levels of mtDNA or total DNA were quantitated using a Nanodrop 2000 Spectrophotometer (Thermo Fisher Scientific).

\section{Quantitative Reverse Transcriptase-Polymerase Chain Reaction Analysis}

Splenic mRNA levels of IL-1 $\beta$ were assessed by quantitative reverse transcriptase-polymerase chain reaction. In brief, total RNA was isolated from spleens using the RNeasy Mini Kit (Qiagen) according to the manufacturer's instructions. Complementary DNA standards were purchased from Bio-Rad Laboratories and actin was selected as a housekeeping gene for reference. Messenger RNA levels were quantified using the $2(-\Delta \Delta \mathrm{Ct})$ relative quantification method as previously described. ${ }^{7,15}$

\section{Statistical Analysis}

All data are presented as mean \pm standard error of the mean. Groups were compared using 1-way analysis of variance followed by $t$ test for unpaired data with Bonferroni correction.

\section{RESULTS}

\section{Depletion of Either HMGB1 or cfDNA Reduced} Myocardial IRI, but No Additive Effect in Protection When Both Were Depleted

C57BL/6 WT mice underwent 40 minutes of ischemia and 60 minutes of reperfusion. Anti-HMGB1 mAb at a dose of $1 \mu \mathrm{g} / \mathrm{g}$ body weight or DNase I at a dose of $30 \mathrm{mU} / \mathrm{g}$ body weight administered 5 minutes before the onset of reperfusion reduced IS (reported as \%RR) by approximately half to $24.3 \% \pm 3.5 \%$ and $29.0 \% \pm 5.2 \%$, respectively $(P<.05$ vs control $54.3 \% \pm 3.4 \%$ ). However, combined treatment with both DNase I and anti-HMGB1 mAb did not further attenuate IS $(29.3 \% \pm 4.9 \% ; P$ value not significant vs individually treated group). RRs were equal among all groups (Figure 1, $A$, and Figure E1). In control mice with $40^{\prime} / 5^{\prime}$ IRI, plasma was harvested at 5 minutes after reperfusion. Aliquots of plasma were treated either with PBS $(1 \mu \mathrm{L} / \mu \mathrm{L}$ plasma), DNase I $(1 \mathrm{mU} / \mu \mathrm{L}$ plasma), or proteinase $\mathrm{K}(0.02 \mu \mathrm{g} / \mu \mathrm{L}$ plasma). The DNase I treatment did not reduce plasma levels of HMGB1 ( $P$ value not significant vs PBS-treated) 

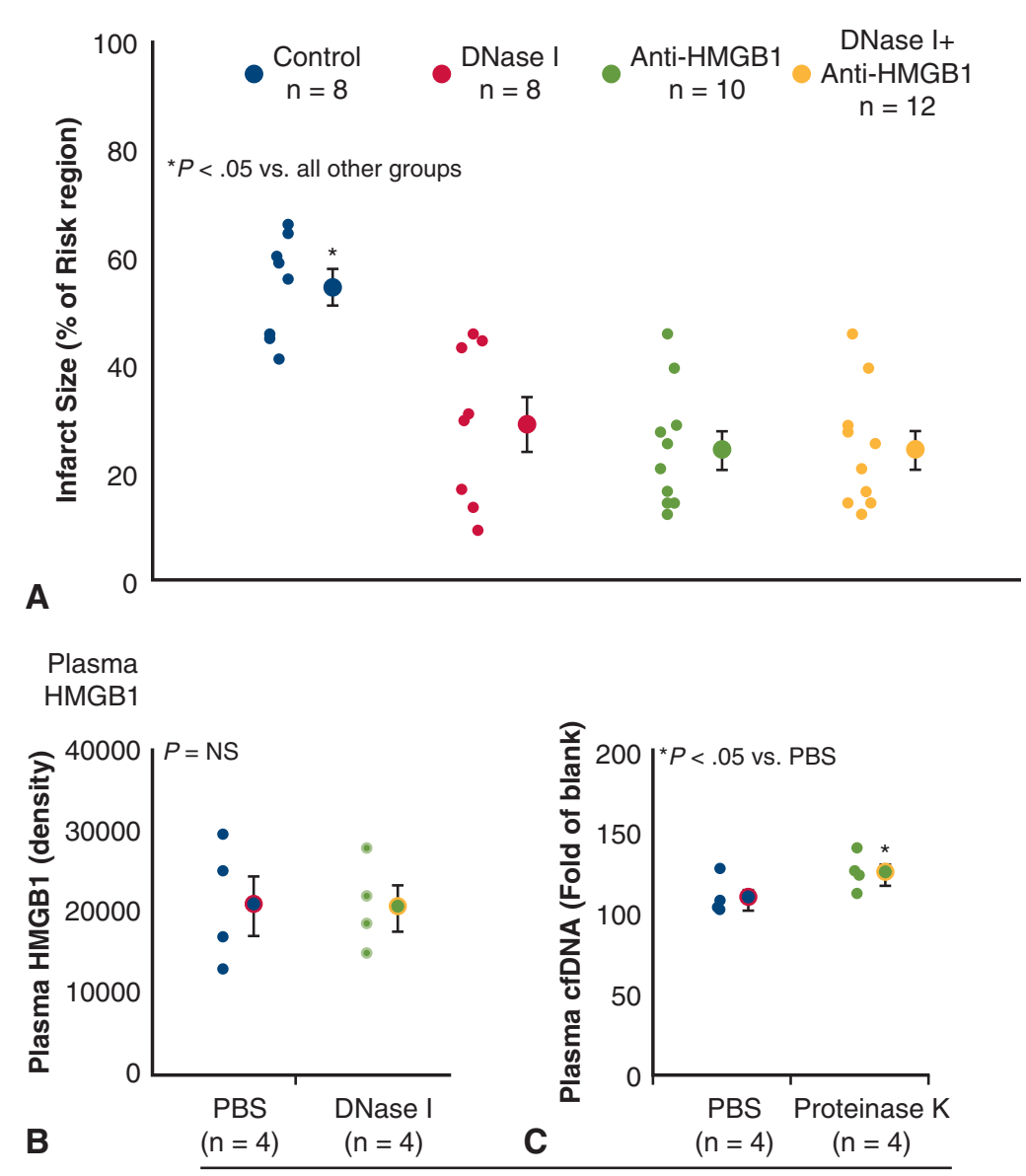

Plasma from $40^{\prime} / 5^{\prime}$ mouse

FIGURE 1. A, Role of high-mobility group box 1 (HMGB1) or cell-free DNA ( $c f D N A)$ in myocardial ischemia-reperfusion injury (IRI). C57BL/6 mice underwent 40 minutes of ischemia and 60 minutes of reperfusion. Phatho blue (Heucotech, Fairless Hill, Pa) was used to stain the heart for delineation of infarct size ( $\%$ of risk region), ischemic risk region ( $\%$ of left ventricle). Anti-HMGB1 monoclonal antibody at a dose of $1 \mu \mathrm{g} / \mathrm{g}$ mouse weight or dioxyribonuclease I (DNase I) at a dose of $30 \mathrm{mU} / \mathrm{g}$ mouse weight administered 5 minutes before the onset of reperfusion. B, Effect of cfDNA depletion on plasma HMGB1. C, Effect of protein depletion on plasma cfDNA. NS, Not significant; PBS, phosphate buffered saline.

(Figure $1, B$ ). After using proteinase $\mathrm{K}$ to digest proteins (including HMGB1) in the plasma, plasma cfDNA exhibited a small but significant increase of $14.6 \%$ $(P<.05$ vs PBS-treated) (Figure $1, C)$.

\section{Ischemic Myocardium Releases Free HMGB1 and cfDNA Into the Bloodstream During Reperfusion}

C57BL/6 WT mice underwent either sham thoracotomy without IRI, or 40 minutes of LCA occlusion. After 40 minutes of ischemia, the ischemic region of the heart showed higher cfDNA fluorescence intensity compared with the nonischemic region under IVIS Lumina fluorescence imaging. The posterior wall showed a similar low intensity across all groups (Figure 2, A). Homogenates of these same left ventricular sections showed significantly increased cfDNA in the anterior walls of the IRI groups but not in the posterior walls upon fluorescence imaging. The cfDNA levels appeared to peak at 15 minutes after reperfusion (Figure 2, B). Parallel groups of C57BL/6 WT mice underwent sham thoracotomy, as well as $40^{\prime} / 5^{\prime}$ and $40^{\prime} / 15^{\prime}$ ischemia/reperfusion. Hearts were harvested and cfDNA was extracted from the left ventricle posterior and anterior walls. The cfDNA levels in the posterior wall were similar among the sham and ischemia/reperfusion groups. At the end of $40^{\prime} / 5^{\prime}$ ischemia/reperfusion, anterior wall cfDNA was significantly increased to $0.66 \pm 0.04 \mu \mathrm{g} / \mathrm{g}$ protein $(P<.05 \mathrm{vs}$ sham anterior wall, $0.33 \pm 0.01 \mu \mathrm{g} / \mathrm{g}$ ). At 15 minutes after reperfusion, cfDNA in the anterior wall increased further to $1.17 \pm 0.13 \mu \mathrm{g} / \mathrm{g}$ ( $P<.05$ vs sham and $40^{\prime} / 5^{\prime}$ group $)$, but no increase was detected in the posterior wall (Figure 2, $C$ ).

Cardiac coronary perfusates from $10^{\prime} / 0^{\prime}$ hearts showed a modest but significant increase in levels of HMGB1 but not cfDNA. In contrast, 40 minutes of ischemia robustly increased both HMGB 1 and cfDNA levels in the cardiac perfusates $\left(P<.05\right.$ vs sham and $10^{\prime} / 0^{\prime}$ groups, Figure $3, A$ and $B$ ). Plasma isolated from $40^{\prime} / 0^{\prime}$ mice had similar levels of HMGB1 as plasma from sham animals. Plasma 


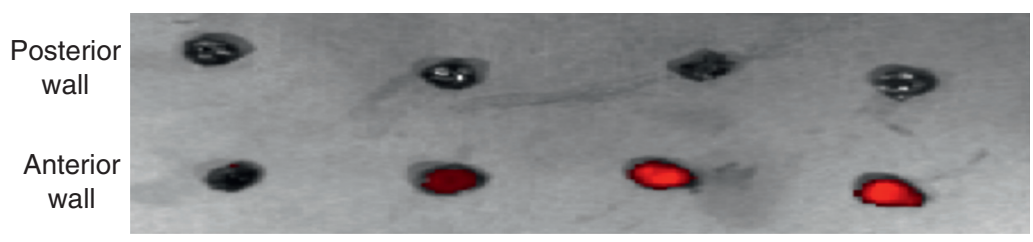

A

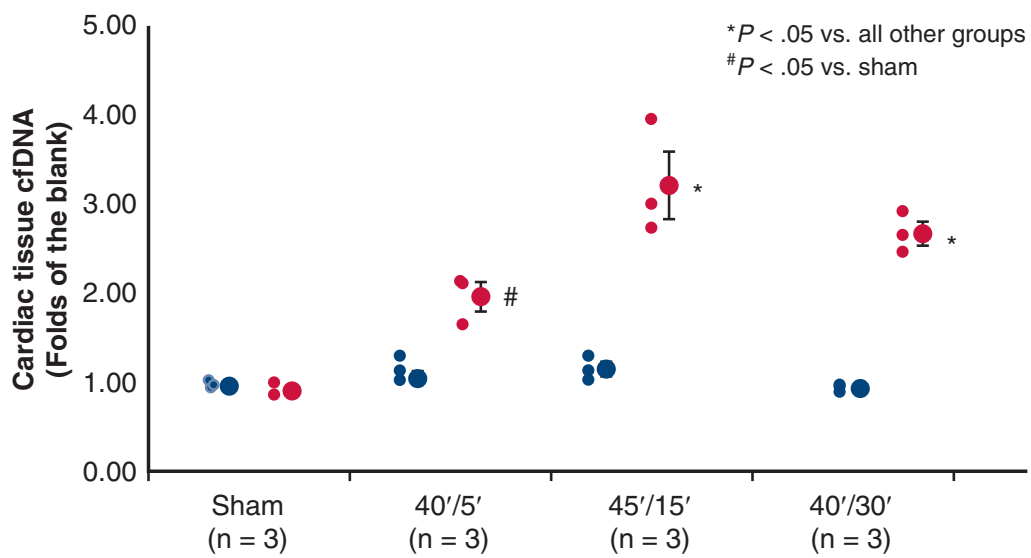

- Non-ischemic posterior wall Ischemic anterior wall

B

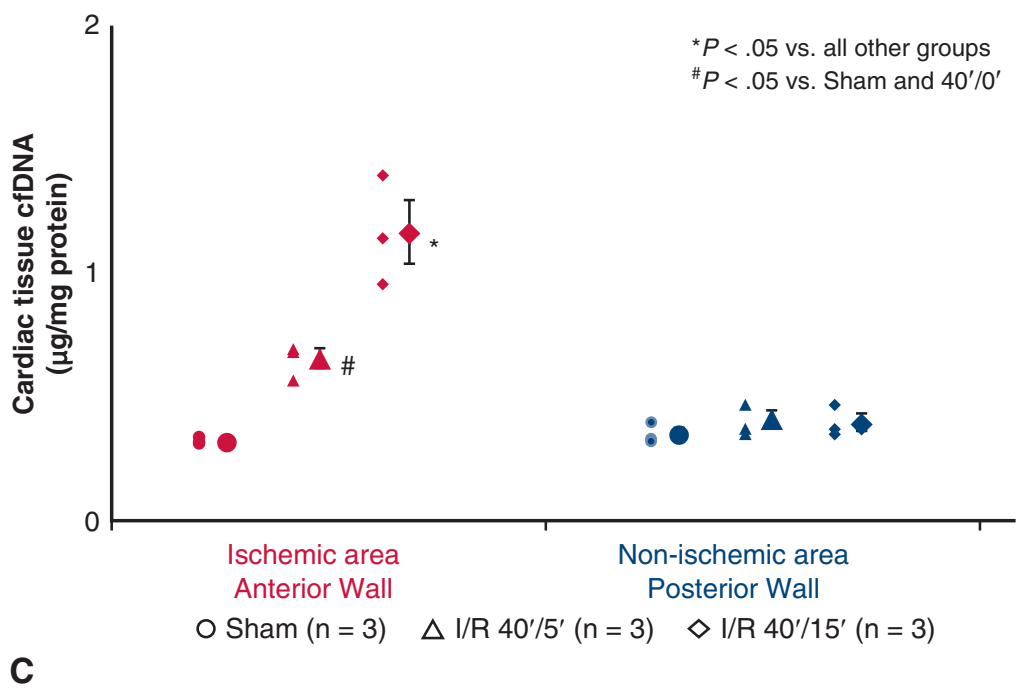

FIGURE 2. Levels of free high-mobility group box 1 (HMGB1) and cell-free DNA ( $c f D N A$ ) in myocardial tissue during ischemia/reperfusion (I/R) injury. C57BL/6 mice underwent either sham thoracotomy or I/R. Sytox green (Thermo Fisher, Waltham, Mass) was injected via intravenous bolus at a dose of $50 \mu \mathrm{L} 1 \mathrm{mM} 1$ minute before reperfusion. The heart was harvested after injection in sham mice, and 5 minutes, 15 minutes, or 30 minutes following reperfusion. The left ventricle was cut into nonischemic posterior wall and ischemic anterior wall. A, Fluorescence of left ventricle anterior and posterior walls imaged under IVIS Lumina Imaging System (PerkinElmer, Akron, Ohio). B, Levels of cfDNA in the homogenates of the left ventricle anterior and posterior wall were measured using photometer. C, cfDNA was extracted from the left ventricle posterior and anterior walls, respectively, in sham, $40^{\prime} / 5^{\prime}$, and $40^{\prime} / 15^{\prime}$ hearts. The cfDNA was quantitatively measured using Nanodrop 2000 Spectrophotometer (Thermo Fisher Scientific, Waltham, Mass).

isolated from $10^{\prime} / 30^{\prime}$ mice showed a small but significant increase in HMGB1 levels compared with sham and $40^{\prime} / 0^{\prime}$ plasma $(P<.05)$. HMGB1 levels in $40^{\prime} / 30^{\prime}$ plasma were far more significantly increased to more than 4 times that observed in other groups. There was no increase in the plasma cfDNA in sham, $10^{\prime} / 30^{\prime}$, or $40^{\prime} / 0^{\prime}$ groups $(P$ value not significant). However, there was a $>10$-fold increase in plasma cfDNA in $40^{\prime} / 30^{\prime}$ mice compared with any other group $(P<.05)$ (Figure 3, $C$ and $D$ ). 

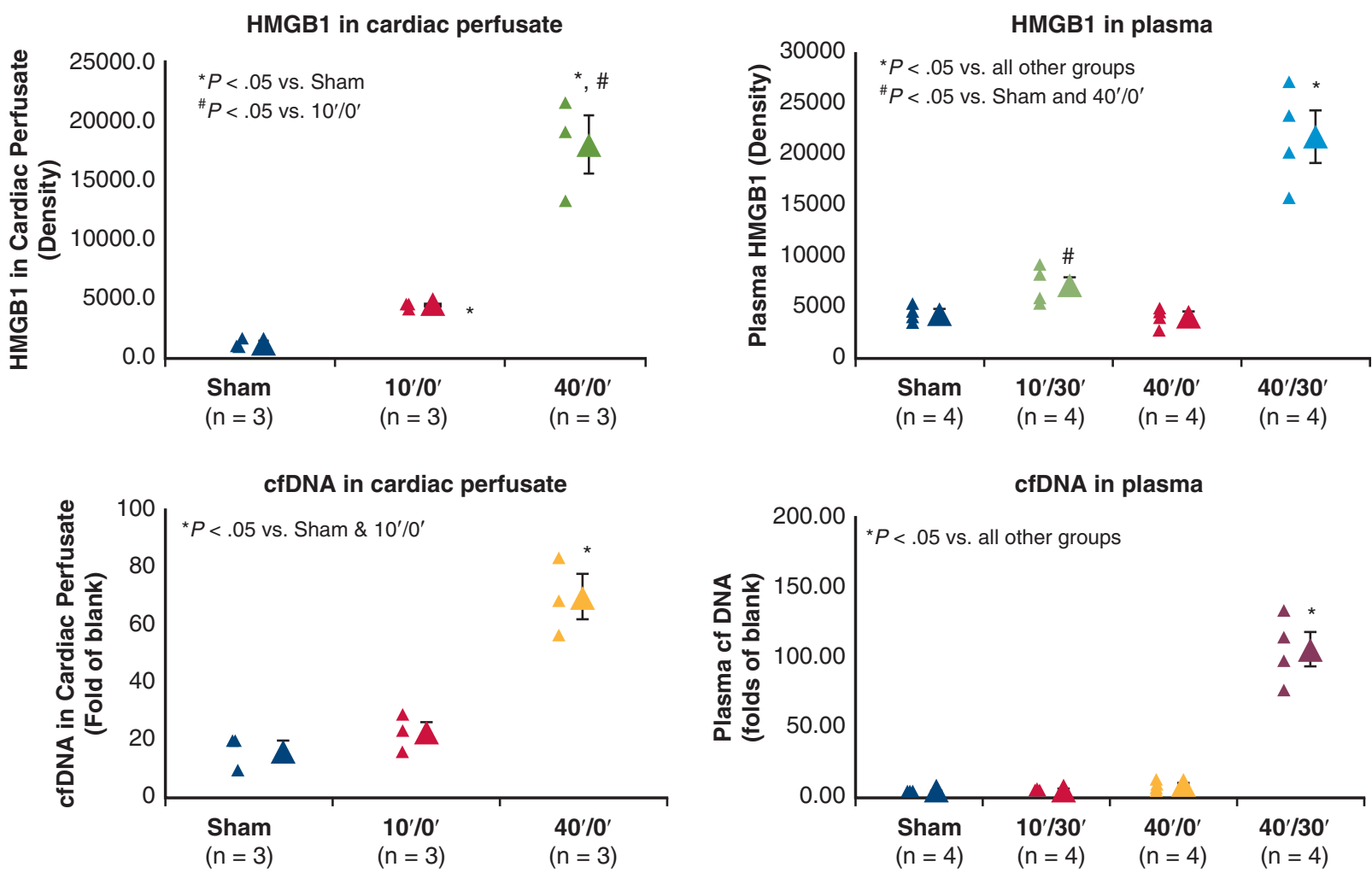

FIGURE 3. Level of free high-mobility group box 1 (HMGB1) and cell-free DNA ( $c f D N A)$ in coronary perfusate and plasma during ischemia-reperfusion injury (IRI). Left column, Cardiac coronary perfusate was obtained by antegrade perfusing of the heart via catheter through the ascending aorta. In the perfusate, the level of HMGB1 was measured by Western blot and the level of cfDNA was measured using Sytox Green (Thermo Fisher, Waltham, Mass) and photometry. Right column, The blood sample was obtained during IR by puncturing the right ventricle. The plasma level of HMGB1 was measured by Western blot and the level of cfDNA was measured using Sytox green and photometry.

\section{Exogenous Cardiac Coronary Perfusate From 40 Minutes Ischemic Mice Exacerbated Myocardial IS in $20^{\prime} / 60^{\prime}$ Mice}

Cardiac perfusate was acquired from $10^{\prime} / 0^{\prime}$ or $40^{\prime} / 0^{\prime}$ hearts of C57BL/6 WT mice. The cardiac perfusate was used to treat 3 groups of C57BL/6 WT mice that underwent 20 minutes of ischemia and 60 minutes of reperfusion. The mice treated with $10^{\prime} / 0^{\prime}$ perfusate had an IS of $5.1 \% \pm 1.0 \%$. The mice treated with $40^{\prime} / 0^{\prime}$ perfusate had significantly increased IS when compared with control mice $(12.8 \% \pm 2.9 \% ; P<.05$ vs control). The IS-exacerbating effect of $40^{\prime} / 0^{\prime}$ perfusate disappeared in splenectomized mice $(5.5 \% \pm 1.1 \%)$ (Figure 4). Risk regions were similar among all groups (Figure E2).

\section{Exogenous Plasma From 40 $/ 5^{\prime}$ Ischemia/Reperfusion Mice Exacerbated Myocardial IS in 20'/60' Mice}

Plasma was acquired from $10^{\prime} / 5^{\prime}$ or $40^{\prime} / 5^{\prime}$ ischemia/ reperfusion C57BL/6 WT mice. The $40^{\prime} / 5^{\prime}$ plasma was treated either with immunoprecipitation to deplete the HMGB1 or with DNase I ( $1 \mathrm{mU} / \mu \mathrm{L}$ plasma) to deplete the cfDNA. The $40^{\prime} / 5^{\prime}$ plasma significantly exacerbated IS when compared with control mice treated with $10^{\prime} / 5^{\prime}$ plasma $(19.9 \% \pm 4.3 \%$ vs $1.9 \% \pm 0.5 \% ; P<.05)$. The infarct-exacerbating effect of $40^{\prime} / 5^{\prime}$ plasma disappeared in splenectomized WT mice, RAGE KO mice, and TLR9 KO mice and $(2.6 \% \pm 0.8 \%$, $2.1 \% \pm 0.6 \%$, and $4.2 \% \pm 1.3 \% ; P$ values not significant vs control mice). The infarct-exacerbating effect of $40^{\prime} / 5^{\prime}$ plasma also disappeared if either HMGB1 or cfDNA was depleted from it (Figure 5, A). Corresponding TTC blue staining of the heart delineated larger IS in $40^{\prime} / 5^{\prime}$ plasma-treated WT mice than in the rest groups (Figure 5, $A$, upper panel). Risk regions were similar among all groups (Figure E3).

The $40^{\prime} / 5^{\prime}$ plasma deficient of HMGB1 by immunoprecipitation contained had significantly less cfDNA by $15 \%$ compared with untreated $40^{\prime} / 5^{\prime}$ plasma $(P<.05)$ (Figure $5, B$ ). Plasma treated with proteinase $\mathrm{K}$ had significantly increased cfDNA by $14 \% \quad(P<.05)$ (Figure $5, B$ ). Precipitated HMGB1 from the $40^{\prime} / 5^{\prime}$ plasma contained barely detectable cfDNA $(P<.05$ vs HMGB1-depleted plasma and $P$ value not significant vs blank). However, after digesting the HMGB1 with proteinase $\mathrm{K}$, the cfDNA level more than doubled $(P<.05)$ (Figure 5, B). 


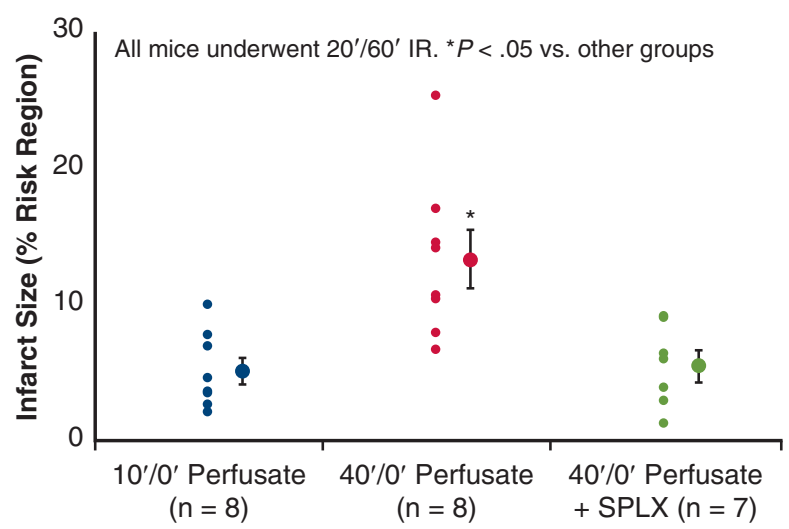

FIGURE 4. Role of exogenous cardiac coronary perfusate in exacerbating myocardial infarct size. Perfusate acquired from $10^{\prime} / 0^{\prime}$ or $40^{\prime} / 0^{\prime}$ donor hearts was administered via intravenous bolus 5 minutes before reperfusion at a dose of $2 \mu \mathrm{L} / \mathrm{g}$ recipient mouse. The recipient mice underwent $20^{\prime} / 60^{\prime}$ ischemia-reperfusion (IR). SPLX, Splenectomy 5 minutes before occlusion of left coronary artery.

\section{Exogenous Plasma From 40'/5' Ischemia/Reperfusion Mice Activated the Splenic Leukocytes}

Three groups of normal mice were treated with either PBS, $10^{\prime} / 5^{\prime}$ plasma, or $40^{\prime} / 5^{\prime}$ plasma. The exogenous $40^{\prime} / 5^{\prime}$ plasma significantly increased splenic tissue expression of IL- $1 \beta$ protein and messenger RNA $(P<.05$ vs $10^{\prime} / 5^{\prime}$ plasma-treated mice) (Figure 6).

\section{Role of Exogenous HMGB1 and mtDNA in Myocardial Infarct Exacerbation in $20^{\prime} / 60^{\prime}$ Mice}

C57BL/6 WT mice and RAGE KO mice underwent $20^{\prime} / 60^{\prime}$ ischemia/reperfusion and were treated upon reperfusion with either mouse recombinant HMGB1 (rHMGB1) at a dose of $0.1 \mu \mathrm{g} / \mathrm{g}$ mouse weight and/or mtDNA at a dose of $0.5 \mu \mathrm{g} / \mathrm{g}$ mouse weight. Neither rHMGB1 nor mtDNA could exacerbate IS in C57BL/6 WT mice when the individual aged was administered alone $(6.0 \% \pm 0.9 \%$ and $3.0 \% \pm 1.4 \%$ vs control $4.3 \% \pm 0.6 \%$; $P$ value not significant). However, combined treatment with both rHMGB 1 and mtDNA dramatically increased IS 2-fold $(16.1 \% \pm 3.5 \% ; P<.05)$. The infarct-exacerbating effect of this combined treatment disappeared in RAGE KO mice and splenectomized WT mice and $(4.4 \% \pm 1.4 \%$ and $3.7 \% \pm 1.4 \% ; P$ value not significant vs control) (Figure 7, A). Risk regions were similar among all groups (Figure E4).

To investigate whether HMGB1/RAGE pathway facilitates the cfDNA entering the splenic leukocytes, parallel groups of WT and RAGE KO mice were treated with PBS, rHMGB1, and/or WT normal liver mtDNA. Splenic tissue cfDNA levels were evaluated 30 minutes after intravenous injection. Treatment with rHMGB1 did not increase splenic cfDNA when compared with PBS-treated mice $(P$ value not significant). Treatment with mtDNA significantly increased the splenic cfDNA level by $3.6 \%$ when compared with treatment of HMGB1 $(P<.05)$. A significantly more increase in splenic cfDNA was found after combined treatment with both rHMGB1 and mtDNA, increased by $9.2 \%$ when compared with HMGB 1 alone $(P<.05)$ and by $5.4 \%$ when compared with mtDNA alone $(P<.05)$. This additional increase in cfDNA with combined treatment disappeared in RAGE KO mice $(P<.05$ when compared with combined treatment in WT mice) (Figure $7, B$ ). The plasma cfDNA was not detectable by Spectrophotometer. Using Sytox Green probe, the plasma cfDNA were evaluated and found no difference across all groups with or without mtDNA treatment ( $P$ value not significant) (Figure 7, $C$ ).

\section{DISCUSSION}

The present study demonstrates, for the first time, that the post-IRI is triggered by the index ischemic myocardial injury. Necrotic ischemic myocardial injury is prerequisite for postischemic reperfusion necrotic injury. Necrotic cardiomyocytes release DAMPs that enter into the circulation, activate the spleen to exacerbate inflammatory response, and eventually exacerbate IS during reperfusion. Among the DAMPs, both HMGB1 and cfDNA play critical roles in exacerbating infarction during postischemic reperfusion. The current study demonstrated that both HMGB1 and cfDNA are indispensable in activating the inflammatory response by engaging to a pathway dependent on RAGEs and TLR9. Depletion of either HMGB1 or cfDNA upon reperfusion suffices to abrogate the post-IRI.

Increasing body of evidence implicates the acute inflammatory response as a contributor to reperfusion injury. ${ }^{12,13,16-19}$ Necrotic cardiomyocytes release DAMPs, including HMGB1, heat shock protein 60/70, S100, and mtDNA. ${ }^{7,20-24}$ DAMPs mediate intense innate inflammatory response by acting on TLR 2,4 , and $9^{20-23,25}$ and/or RAGEs. ${ }^{24,26}$ Individual members of the DAMPs, like HMGB1, ${ }^{7,26,27} \mathrm{~S} 100,{ }^{21,24} \mathrm{HSP} 60 / 70,{ }^{28}$ or mtDNA, ${ }^{1,6}$ contributes importantly to myocardial IRI. However, the cross-talk among DAMPs in myocardial IRI remains unknown. It has been demonstrated that HMGB1 plays an important role in mediating myocardial IRI. Our previous study showed that prolonged ischemia produces myocardial necrosis necessary to release high levels of HMGB1, which then enter the bloodstream during reperfusion. The circulating HMGB1 activates splenic leukocytes by engaging RAGE, which ultimately induces the stimulation of neutrophils and neutrophilia. The circulating neutrophils then transmigrate to the previously ischemic myocardium and exacerbate myocardial infarction. ${ }^{7}$ Blockade of HMGB1-RAGE pathway attenuates myocardial infarction. $^{7,27,29}$ Other members of DAMPs—cfDNA/mtDNAhave attracted increased attention for their role in the 


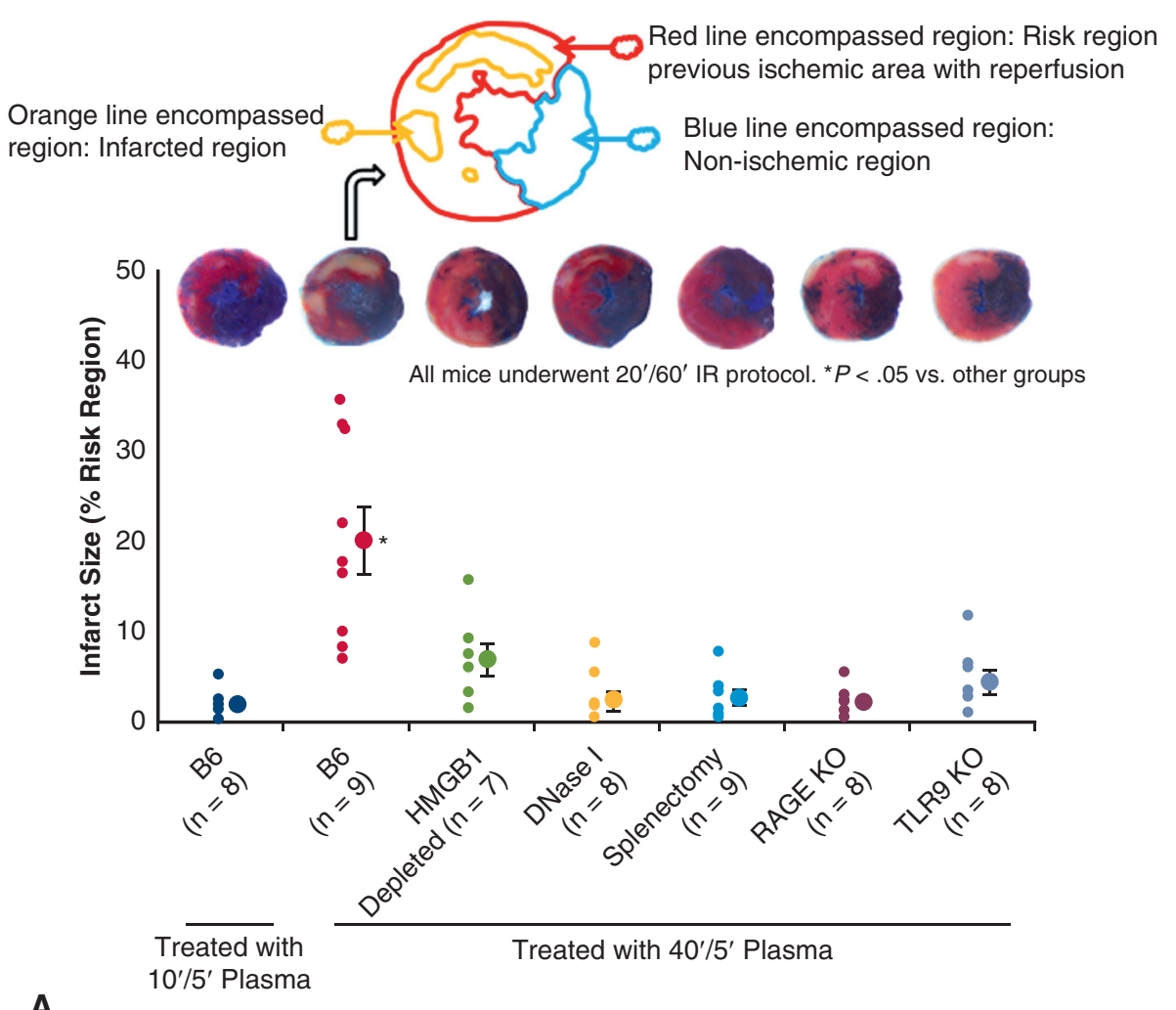

A

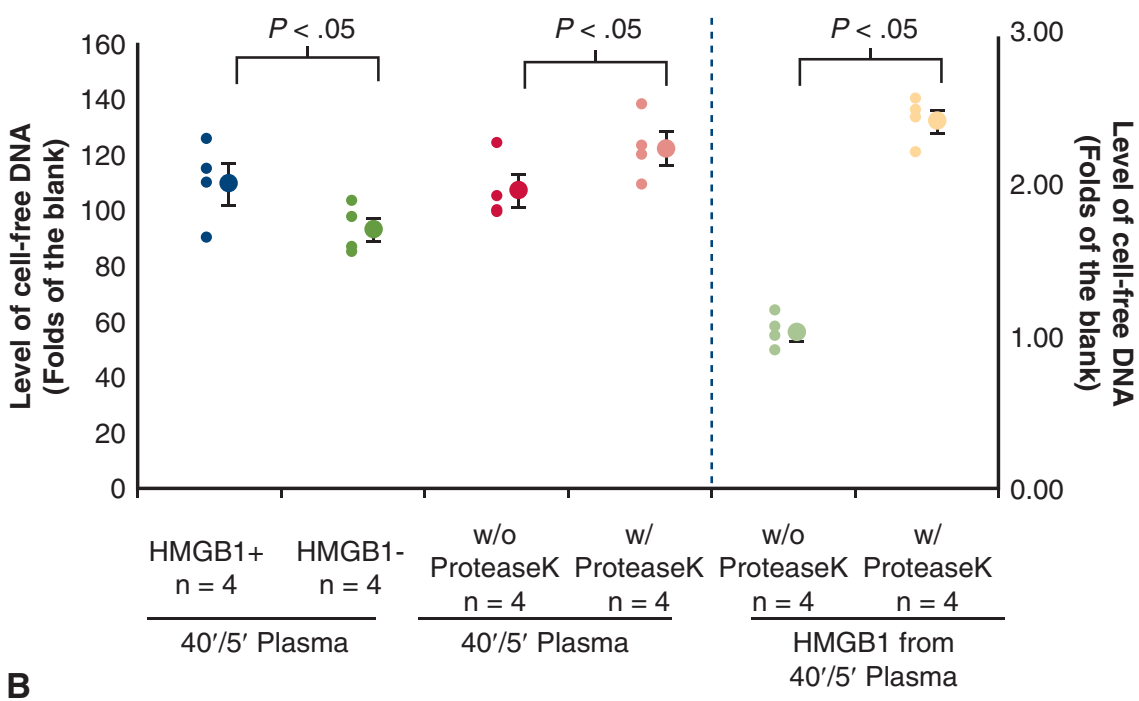

FIGURE 5. Role of exogenous plasma in exacerbating myocardial infarct size. A, Plasma acquired from $10^{\prime} / 5^{\prime}$ or $40^{\prime} / 5^{\prime}$ donor C57BL/6 mice was administered intravenous bolus 5 minutes before reperfusion at a dose of $2 \mu \mathrm{L} / \mathrm{g}$ recipient mouse. The recipient mice underwent $20^{\prime} / 60^{\prime}$ ischemia-reperfusion (IR). Immunoprecipitation was used to deplete high-mobility group box 1 (HMGB1) in the donor plasma; deoxyribonuclease I (DNase I) was used to deplete cell-free DNA in the donor plasma at a dose of $1 \mathrm{mU} / \mu \mathrm{L}$ donor plasma. Upper portion, Representative triphenyltetrazolium chloride/Phthalo blue staining of the middle left ventricular slice. Top, the ischemic area (red), infarct area (yellow), and nonischemic area (blue) are drawn and included area can be calculated. B, Level of cell-free DNA in the 40'/5' plasma with different treatments using Sytox Green (Thermo Fisher, Waltham, Mass). (Results of proteinase K-treated plasma are also reported in Figure 1, C). RAGE KO, Receptor for advanced glycation end products knockout; TLR9 KO, Toll-like receptor 9 knockout.

cardiovascular system. ${ }^{2,20,30}$ Elevated cfDNA has negative prognostic survival in patients with cardiac arrest ${ }^{30}$ and myocardial infarction. ${ }^{3,31}$ Patients with acute myocardial infarction have elevated cfDNA, especially mtDNA. ${ }^{2}$ Animal experiments confirm the clinical findings and demonstrate that cfDNA contributes importantly to 

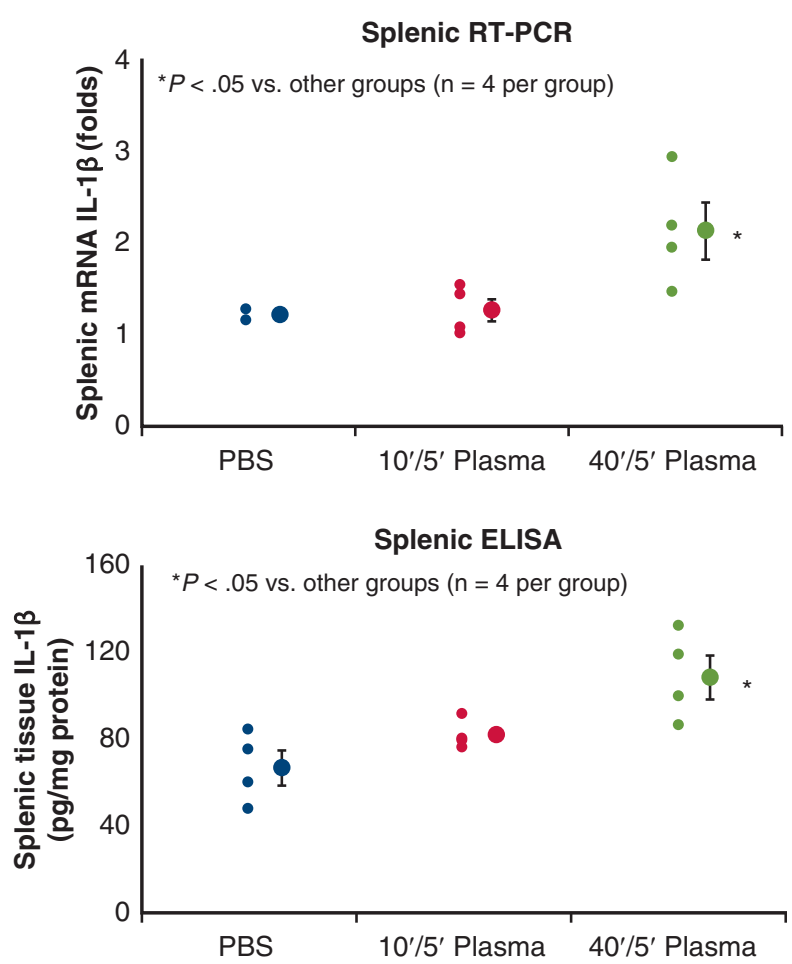

FIGURE 6. Splenic tissue level of interleukin (IL)-1 $\beta$ protein and messenger RNA. Spleen was harvested from sham, $10^{\prime} / 30^{\prime}$, and $40^{\prime} / 30^{\prime}$ mice and homogenized. IL- $1 \beta$ protein and messenger RNA were evaluated by enzyme-linked immunoassay (ELISA) and reverse transcriptase-polymerase chain reaction, respectively. $P B S$, Phosphate buffered saline; $R T C-P C R$, reverse transcriptase-polymerase chain reaction.

myocardial IRI. Furthermore, degradation of cfDNA attenuates myocardial IRI. ${ }^{1,5,6}$ Taken together, both HMGB1 and cfDNA are found to mediate myocardial IRI. Whether these 2 DAMPs work sequentially or parallel in mediating myocardial IRI is unknown. In the current study, we show that treatment upon reperfusion with either HMGB1 mAb or DNase I similarly attenuated myocardial IS in mice who underwent $40^{\prime} / 60^{\prime}$ IRI. However, double treatment did not produce additional more reduction in myocardial IS when compared with the individual treatment (Figure 1). Degrading cfDNA did not alter the concentration of plasma HMGB1 (Figure 1, B). Digesting plasma HMGB1 may slightly increase cfDNA by $15 \%$ (Figure 1, $C$, and Figure 5, B), indicating $85 \%$ of cfDNA is not bound to HMGB1. Degrading either HMGB1 or cfDNA will not significantly decrease their counterpart's levels in the plasma. The results indicate that HMBG1 and cfDNA might work either sequentially on a pathway or confluent on a final common target and they are indispensable components of a signal transduction inducing post-IRI. Blockage either HMGB1 or cfDNA sufficed to interrupt the signal pathway and attenuated myocardial infarction.
It is clear that necrotic cardiomyocytes release DAMPs. It is unclear whether the heart releases the components of the DAMPs simultaneously or not. Furthermore, whether the heart is the only source of DAMPs in the blood during IRI remains unknown. Our previous work has established that myocardial infarct size at 60 minutes of reperfusion attains $95 \%$ of the size at 24 hours postreperfusion in mice. ${ }^{9,11}$ The inflammatory response during the first hour of reperfusion is critical to induce post-IRI. ${ }^{7,9}$ We have also shown that necrotized cardiomyocytes during ischemia release HMGB1 to the bloodstream that subsequently activates splenic leukocytes and triggers inflammatory response during reperfusion. ${ }^{7}$ Again in the current study, we found that freeform HMGB1 was increased in cardiac coronary perfusate with prolonged ischemia (40 minutes) and the plasma HMGB1 was not elevated until reperfusion occurred (Figure 3, upper panel). There was slightly increase in HMGB1 of the cardiac perfusate and plasma in $10^{\prime} / 5^{\prime}-30^{\prime}$ mice. But this increase is likely due to active secretion from residential inflammatory cells, because 10 minutes of ischemia did not induce infarction ${ }^{7}$ and did not release cfDNA (Figure 3, lower panel). Corresponding elevation of cfDNA was found in the 40-minute ischemic cardiac coronary perfusate and $40^{\prime} / 30^{\prime}$ plasma but not in the 10-minute ischemic heart or plasma (Figure 3, lower panel). These results demonstrated that the dramatic increases in myocardial tissue freeform HMGB1 and cfDNA following prolonged ischemia occurs simultaneously and are secondary to myocardial cellular necrosis and nuclear breakdown. Elevation of cfDNA may be more indicative of myocardial necrosis than HMGB1. The results also indicated that the elevated HMGB1 and cfDNA levels in plasma are derived solely from the ischemic heart. By measuring the myocardial tissue cfDNA, we found that cfDNA in the left ventricle posterior wall, nonischemic zone, was low and unchanged during reperfusion. However, cfDNA in the anterior ischemic zone elevated significantly and peaked within 15 minutes of reperfusion. Quantitative evaluation of cfDNA showed similar changes in the posterior and anterior wall (Figure 2, $B$ and $C$ ). Similar trend of changes in the intact heart also found in the fluorescent density as measured by IVIS Lumina Imaging System (Figure 2, A). These results demonstrate that the necrotized myocardium releases cfDNA, which is further aggravated as myocardial infarction accrues during reperfusion.

Our previous study has shown that myocardial homogenate from $40^{\prime} / 0^{\prime}$ heart exacerbates IS of mice with $20^{\prime} / 60^{\prime}$ ischemia/reperfusion. ${ }^{7}$ In the current study, we found that cardiac coronary perfusate from $40^{\prime} / 0^{\prime}$ heart or plasma from $40^{\prime} / 5^{\prime}$ ischemia/reperfusion mice dramatically increased the myocardial infarct size in $20^{\prime} / 60^{\prime}$ ischemia/ reperfusion mice and their infarct-exacerbating effect 

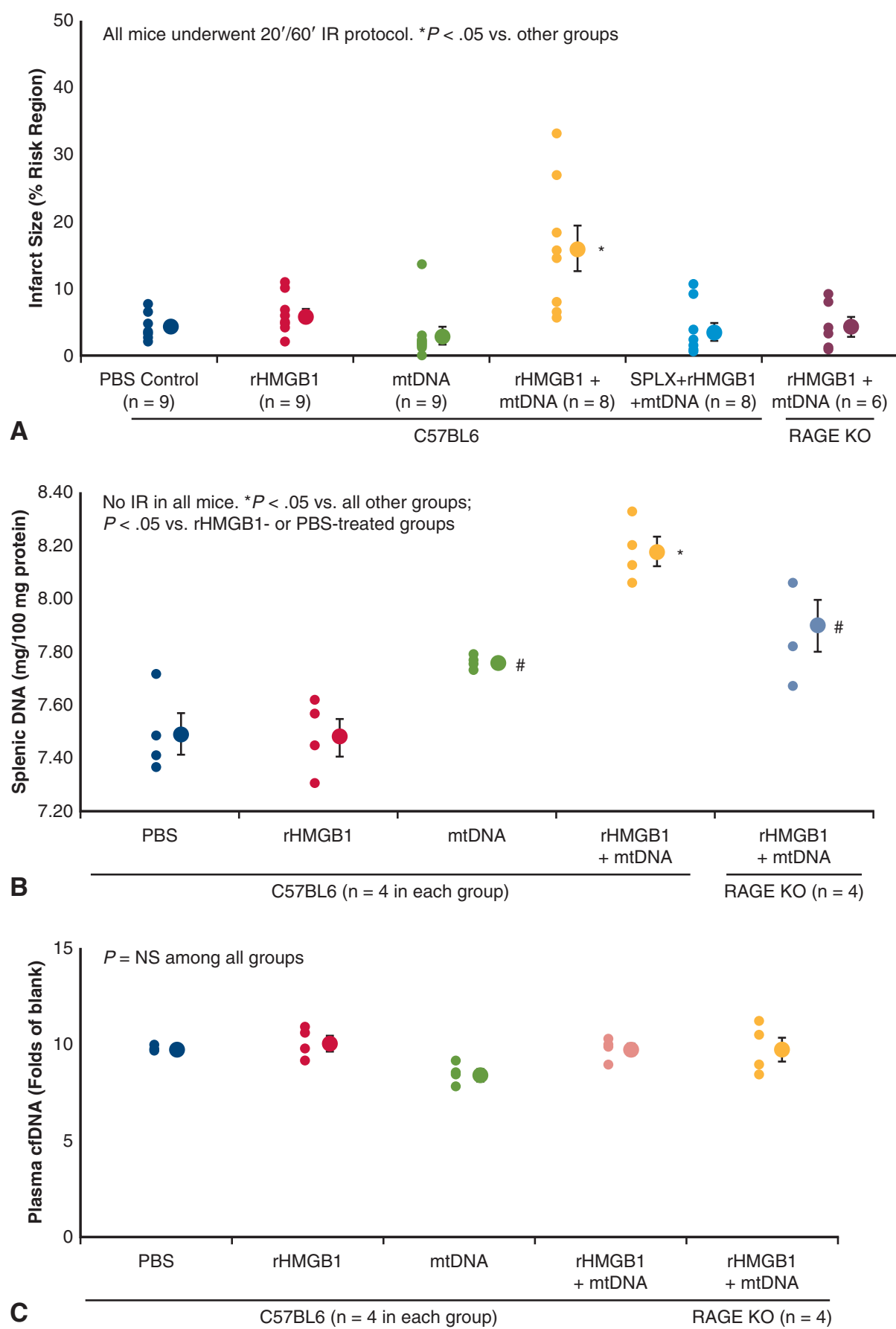

FIGURE 7. Role of exogenous recombinant high-mobility group box 1 ( $r H M G B 1)$ and mitochondrial DNA ( $m t D N A)$ in exacerbating myocardial infarct size. C57BL/6 mice and receptor for advanced glycation end products knockout $(R A G E K O)$ mice underwent $20^{\prime} / 60^{\prime}$ ischemia reperfusion $(I R)$ injury and were treated upon reperfusion with either mouse rHMGB1 at a dose of $0.1 \mu \mathrm{g} / \mathrm{g}$ mouse weight and/or mouse mtDNA at a dose of $0.5 \mu \mathrm{g} / \mathrm{g}$ mouse weight. A, Combined treatments 5 minutes before reperfusion exacerbated infarct size in C57BL/6 mice but not in RAGE KO or splenectomized C57BL/6 mice. B, 30 minutes after treatment in mice without IR injury, combined treatments increased splenic tissue DNA level in C57BL/6 mice more significantly than combined treatment in RAGE KO mice or the individual treatment with either rHMGB1 or mtDNA in C57BL/6 mice. C, 30 minutes after treatment in mice without IR injury, the plasma level of cfDNA was similar among the 5 groups. SPLX, Splenectomy 5 minutes before occlusion of left coronary artery; $P B S$, phosphate buffered saline.

disappeared in mice without the spleen and in RAGE KO and TLR9 KO mice (Figure 4 and Figure 5, A). Furthermore, pretreatment of the $40^{\prime} / 5^{\prime}$ plasma to deplete either HMGB1 or cfDNA abrogates its effect of infarct exacerbation (Figure $5, A$ ). The total dose of DNase I was $1 \mathrm{mU} / \mu \mathrm{L}$ donor plasma or $2 \mathrm{mU} / \mathrm{g}$ recipient mouse weight, which was 


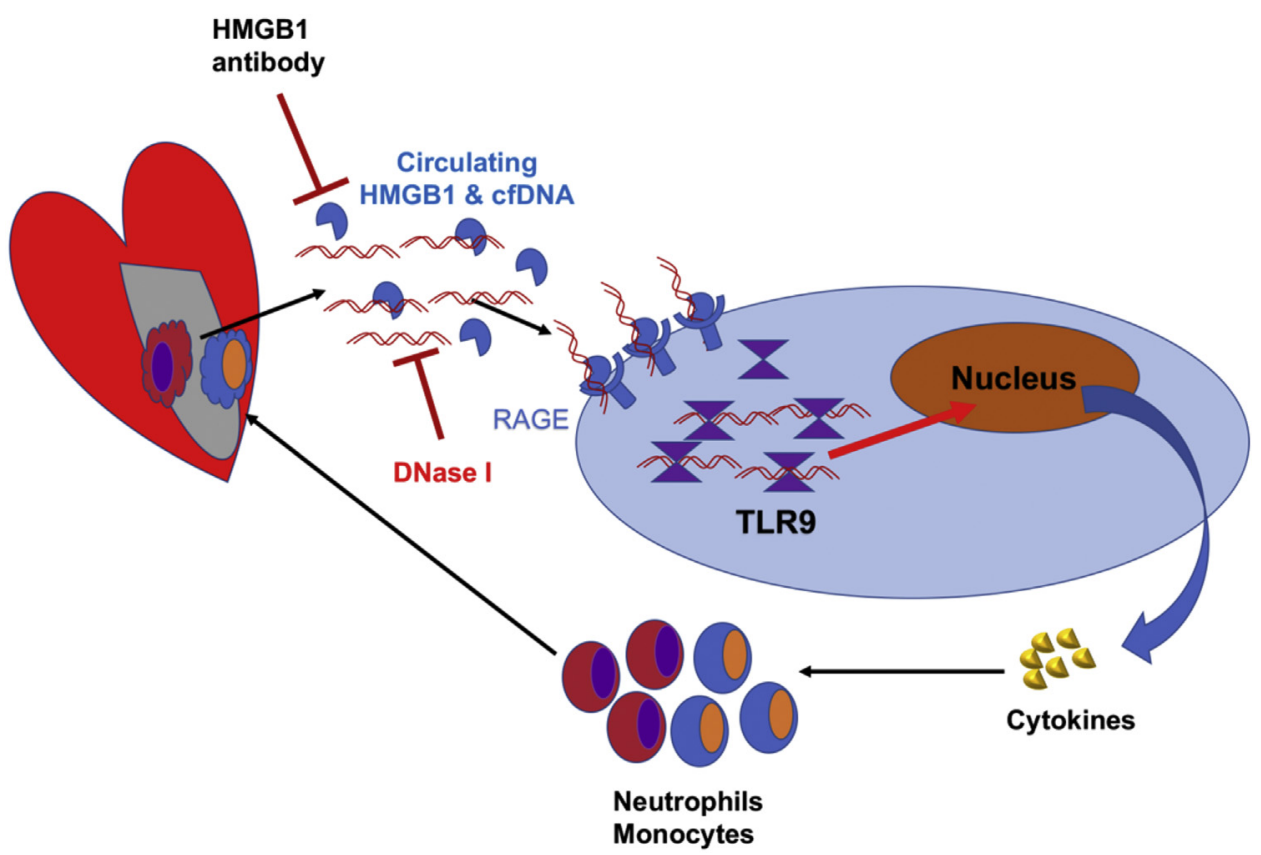

FIGURE 8. Schematic mechanism of the free high-mobility group box 1 (HMGB1) and cell-free DNA (cfDNA) complex in acute myocardial ischemia-reperfusion injury. DNase I, Deoxyribonuclease I; RAGE, receptor for advanced glycation end products; TLR9, Toll-like receptor 9.

significantly less than that was used for global treatment $(30 \mathrm{mU} / \mathrm{g}$ ) (Figure 1), and at this lower dose, DNase I did not attenuate infarct size in $40^{\prime} / 60^{\prime}$ ischemia/reperfusion mice (Figure E5). These results further confirmed that the ischemically necrotized cardiomyocytes released HMGB1 and DNA simultaneously into the bloodstream and these 2 substances worked together to elaborate an enhanced inflammatory response by activating the spleen (Figure 6) and eventually exacerbate myocardial infarct size (Figure 5, A). Again, no reperfusion injury will occur if missing any 1 of the 2 substances in the circulation.

Circulating DNA immune complex plays critical roles in many immune diseases. In the present study, a $15 \%$ of difference in cfDNA in the $40^{\prime} / 5^{\prime}$ plasma when either HMGB1 was precipitated (lost with HMGB1) or protein was digested (released from binding protein). In isolated HMGB 1 by immunoprecipitation, cfDNA was not detectable ( $P$ value not significant vs blank). However, after digesting the HMGB1 with proteinase $\mathrm{K}$, significant more cfDNA released (more than doubled the untreated; $P<.05$ ) (Figure $5, B$ ). These results indicated that about $15 \%$ cfDNA were bound to proteins, mostly HMGB1, in the blood during reperfusion. It is unclear whether unbounded HMGB1 and cfDNA or the bounded complex of the 2 contribute more to the post-IRI. DNase I depleted unbounded cfDNA, not the bounded DNA, to attenuate post-IRI. ${ }^{32}$ We found that DNase I depleted unbounded cfDNA without changes of the HMGB1 level in the plasma (Figure 1, $B$ ) but significantly attenuated myocardial infarct size in $40^{\prime} / 60^{\prime}$ ischemia/reperfusion mice (Figure $1, A$ ). The results support the notion that bounded cfDNA is not critical in causing post-IRI.

By using exogenous rHMGB1 and mtDNA, we further confirmed that individual treatment with either rHMGB1 or mtDNA did not exacerbate the infarct size in $20^{\prime} / 60^{\prime}$ ischemia/reperfusion mice. However, combined treatment with both rHMGB1 and mtDNA significantly increased the infarct size in intact mice but not in splenectomized mice and RAGE KO mice (Figure 7, A). Taken all these together, the current study demonstrated that prolonged ischemia causes ischemic necrosis. During reperfusion, the necrotized cardiomyocytes release dissociated HMGB1 and DNA into the bloodstream. The 2 DAMPs work interdependently to activate the spleen-mediated inflammatory responses via RAGE and exacerbate IS during reperfusion.

Recent studies reported that cfDNA, mostly mtDNA, is elevated during acute myocardial infarction., ${ }^{2,31}$ cfDNA enhances myocardial IRI likely by activating TLR9. ${ }^{1,5}$ TLR9 is expressed by numerous immune cells, such as lymphocytes, monocytes, natural killer cells, and dendritic cells. TLR9 is expressed intracellularly, within the endosomal compartments, and functions to initiate proinflammatory response following activation. ${ }^{33-35}$ Both HMGB1 and DNA can bind to RAGE directly and HMGB1 is expected to change the DNA binding properties to RAGE and facilitate DNA internalization. ${ }^{36-38}$ However, it is not conclusive on how HMGB1 facilitates this transportation; either HMGB1 binds RAGE to increase the permeability of RAGE to nucleotides or HMGB1 binds 
nucleotides first and then RAGE to internalize nucleotides. Our study showed that $<15 \%$ of cfDNA binds to the freeform HMGB1 in the plasma (Figure 5, B). Exogenous rHMGB1 and mtDNA did not bind together when they were mixed (data not shown). Five minutes after intravenous injection of exogenous mtDNA, the plasma level of cfDNA was 4 times as much as PBS treated mice $(P<.05)$ (Figure E6). Thirty minutes after injection of mtDNA with or without simultaneous rHMGB1 injection, the plasma level of cfDNA in WT and RAGE KO mice was not different from those treated with either PBS or HMGB1 injection (Figure 7, C). However, the splenic tissue cfDNA levels were significantly elevated in mtDNA-treated mice; furthermore, rHMGB1 significantly increased the splenic tissue cfDNA level in mtDNA-treated WT mice but not in RAGE KO mice (Figure 7, B). The elevation of splenic tissue cfDNA level in mtDNA-treated mice is likely an increase of cfDNA in the splenic interstitial space due to a surge in plasma mtDNA (Figure E6) HMGB1 further increases the splenic tissue cfDNA by binding to RAGE to facilitate intracellular transportation of cfDNA. These results underline the notion that HMGB1 binds RAGE to facilitate DNA transportation into the inflammatory cells (Figure 8).

\section{Study Limitations}

Besides HMGB1 and cfDNA, other components of DAMPs as well as small interfering RNA that are also released by the necrotized cardiomyocytes are not investigated in the current study. We could not exclude their role in mediating post-IRI and we hypothesize that they might also contribute to IRI in an interdependent manner as well. The interaction between RAGE and TLR9 as well as the downstream pathway following RAGE and TLR9 was not investigated in the current study. It has been reported that there is crosstalk between RAGE and TLRs in mediating inflammatory responses. Thus the relative contributions of the RAGE and TLR signaling pathways to myocardial IRI will require further study.

\section{Clinical Importance}

The current study demonstrates that if there is no myocardial necrosis during ischemia, there will be no additional myocardial necrosis during reperfusion. Necrotized cardiomyocytes during ischemia release DAMPs into the circulation during reperfusion, which trigger the inflammatory responses and exaggerate the infarct size. Clinically, shortening the ischemic period is the key to reducing the ischemic myocardial necrosis as well as the subsequent reperfusion injury. Depletion of either circulating free HMGB1 or cfDNA upon reperfusion will also help to attenuate the post-IRI and thus may become pharmacologic treatment options in the future.

\section{CONCLUSIONS}

By using a mouse model of acute myocardial IRI, we discovered 2 important DAMPs, HMGB1 and cfDNA, that are released from ischemically infarcted myocardium into the bloodstream during reperfusion, mediate inflammatory response, and exacerbate infarct size via activating splenic RAGE and TLR9. Both HMGB1 and cfDNA are indispensable but work interdependently in activating this inflammatory response. Depleting either HMGB1 or cfDNA upon reperfusion suffices to abrogate post-IRI (Figure 8).

\section{Conflict of Interest Statement}

Authors have nothing to disclose with regard to commercial support.

\section{References}

1. Yang XM, Cui L, White J, Kuck J, Ruchko MV, Wilson GL, et al Mitochondrially targeted endonuclease III has a powerful anti-infarct effect in an in vivo rat model of myocardial ischemia/reperfusion. Basic Res Cardiol. 2015;110:3.

2. Liu J, Cai X, Xie L, Tang Y, Cheng J, Wang J, et al. Circulating cell free mitochondrial DNA is a biomarker in the development of coronary heart disease in the patients with type 2 diabetes. Clin Lab. 2015;61:661-7.

3. Wang L, Xie L, Zhang Q, Cai X, Tang Y, Wang L, et al. Plasma nuclear and mitochondrial DNA levels in acute myocardial infarction patients. Coron Artery Dis. 2015;26:296-300.

4. Marsman G, Zeerleder S, Luken BM. Extracellular histones, cell-free DNA, or nucleosomes: differences in immunostimulation. Cell Death Dis. 2016;7:e2518.

5. Xie L, Liu S, Cheng J, Wang L, Liu J, Gong J. Exogenous administration of mitochondrial DNA promotes ischemia reperfusion injury via TLR9-p38 MAPK pathway. Regul Toxicol Pharmacol. 2017;89:148-54.

6. Yue R, Xia X, Jiang J, Yang D, Han Y, Chen X, et al. Mitochondrial DNA oxidative damage contributes to cardiomyocyte ischemia/reperfusion-injury in rats: cardioprotective role of lycopene. J Cell Physiol. 2015;230:2128-41.

7. Tian Y, Pan D, Chordia MD, French BA, Kron IL, Yang Z. The spleen contributes importantly to myocardial infarct exacerbation during post-ischemic reperfusion in mice via signaling between cardiac HMGB1 and splenic RAGE. Basic Res Cardiol. 2016;111:62.

8. Sharma AK, LaPar DJ, Stone ML, Zhao Y, Kron IL, Laubach VE. Receptor for advanced glycation end products (RAGE) on iNKT cells mediates lung ischemia-reperfusion injury. Am J Transplant. 2013;13:2255-67.

9. Tian Y, French BA, Kron IL, Yang Z. Splenic leukocytes mediate the hyperglycemic exacerbation of myocardial infarct size in mice. Basic Res Cardiol. 2015;110:39.

10. Tian Y, Chen L, Kron IL, French BA, Yang Z. The hyperglycemic exacerbation of myocardial infarct size in mice is mediated by splenocytes. Circulation. 2014; 130:A11735.

11. Yang Z, Linden J, Berr SS, Kron IL, Beller GA, French BA. Timing of adenosine $2 \mathrm{~A}$ receptor stimulation relative to reperfusion has differential effects on infarct size and cardiac function as assessed in mice by MRI. Am J Physiol Heart Circ Physiol. 2008;295:H2328-35.

12. Yang Z, Day YJ, Toufektsian MC, Ramos SI, Marshall M, Wang XQ, et al. Infarct-sparing effect of A2A-adenosine receptor activation is due primarily to its action on lymphocytes. Circulation. 2005;111:2190-7.

13. Yang Z, Day YJ, Toufektsian MC, Xu Y, Ramos SI, Marshall MA, et al. Myocardial infarct-sparing effect of adenosine A2A receptor activation is due to its action on CD4+ T lymphocytes. Circulation. 2006;114:2056-64.

14. Yang Z, Tian Y, Liu Y, Hennessy S, Kron IL, French BA. Acute hyperglycemia abolishes ischemic preconditioning by inhibiting Akt phosphorylation: normalizing blood glucose before ischemia restores ischemic preconditioning. Oxidat Medic Cell Longev. 2013;2013:329183.

15. Tian Y, Zhang W, Xia D, Modi P, Liang D, Wei M. Postconditioning inhibits myocardial apoptosis during prolonged reperfusion via a JAK2-STAT3-Bcl-2 pathway. J Biomed Sci. 2011;18:53.

16. Bainey KR, Armstrong PW. Clinical perspectives on reperfusion injury in acute myocardial infarction. Am Heart J. 2014;167:637-45. 
17. Appleyard RF, Cohn LH. Myocardial stunning and reperfusion injury in cardiac surgery. J Cardiac Surg. 1993;8:316-24.

18. Jang JH, Yamada Y, Janker F, De Meester I, Baerts L, Vliegen G, et al. Anti-inflammatory effects on ischemia/reperfusion-injured lung transplants by the cluster of differentiation 26/dipeptidylpeptidase 4 (CD26/DPP4) inhibitor vildagliptin. J Thorac Cardiovasc Surg. 2017;153:713-24.

19. Jun JH, Song JW, Shin EJ, Kwak YL, Choi N, Shim JK. Ethyl pyruvate is renoprotective against ischemia-reperfusion injury under hyperglycemia. J Thorac Cardiovasc Surg. 2018;155:1650-8.

20. Oka T, Hikoso S, Yamaguchi O, Taneike M, Takeda T, Tamai T, et al. Mitochondrial DNA that escapes from autophagy causes inflammation and heart failure. Nature. 2012;485:251-5.

21. Rohde D, Schon C, Boerries M, Didrihsone I, Ritterhoff J, Kubatzky KF, et al. S100A1 is released from ischemic cardiomyocytes and signals myocardial damage via toll-like receptor 4. EMBO Molec Med. 2014;6:778-94.

22. Zhang W, Lavine KJ, Epelman S, Evans SA, Weinheimer CJ, Barger PM, et al. Necrotic myocardial cells release damage-associated molecular patterns that provoke fibroblast activation in vitro and trigger myocardial inflammation and fibrosis in vivo. J Am Heart Assoc. 2015;4:e01993.

23. Mathur S, Walley KR, Wang Y, Indrambarya T, Boyd JH. Extracellular heat shock protein 70 induces cardiomyocyte inflammation and contractile dysfunction via TLR2. Circ J. 2011;75:2445-52.

24. Cai XY, Lu L, Wang YN, Jin C, Zhang RY, Zhang Q, et al. Association of increased S100B, S100A6 and S100P in serum levels with acute coronary syndrome and also with the severity of myocardial infarction in cardiac tissue of rat models with ischemia-reperfusion injury. Atherosclerosis. 2011;217: 536-42.

25. Zhang Q, Raoof M, Chen Y, Sumi Y, Sursal T, Junger W, et al. Circulating mitochondrial DAMPs cause inflammatory responses to injury. Nature. 2010; 464:104-7.

26. Andrassy M, Volz HC, Igwe JC, Funke B, Eichberger SN, Kaya Z, et al. High-mobility group box-1 in ischemia-reperfusion injury of the heart. Circulation. 2008;117:3216-26.

27. Ding HS, Yang J, Chen P, Yang J, Bo SQ, Ding JW, et al. The HMGB1-TLR4 axis contributes to myocardial ischemia/reperfusion injury via regulation of cardiomyocyte apoptosis. Gene. 2013;527:389-93.
28. Li Y, Si R, Feng Y, Chen HH, Zou L, Wang E, et al. Myocardial ischemia activates an injurious innate immune signaling via cardiac heat shock protein 60 and Toll-like receptor 4. J Biol Chem. 2011;286:31308-19.

29. Huebener P, Pradere JP, Hernandez C, Gwak GY, Caviglia JM, Mu X, et al. The HMGB1/RAGE axis triggers neutrophil-mediated injury amplification following necrosis. J Clin Invest. 2015;125:539-50.

30. Gornik I, Wagner J, Gasparovic V, Milicic D, Degoricija V, Skoric B, et al Prognostic value of cell-free DNA in plasma of out-of-hospital cardiac arrest survivors at ICU admission and 24h post-admission. Resuscitation. 2014; $85: 233-7$.

31. Antonatos D, Patsilinakos S, Spanodimos S, Korkonikitas P, Tsigas D. Cell-free DNA levels as a prognostic marker in acute myocardial infarction. Ann N Y Acad Sci. 2006;1075:278-81.

32. N'Soukpoe-Kossi CN, Diamantoglou S, Tajmir-Riahi HA. DNase I - DNA interaction alters DNA and protein conformations. Biochem Cell Biol. 2008; $86: 244-50$.

33. Martinez-Campos C, Burguete-Garcia AI, Madrid-Marina V. Role of TLR9 in oncogenic virus-produced cancer. Viral Immunol. 2017;30:98-105.

34. Kimura T, Endo S, Inui M, Saitoh S, Miyake K, Takai T. Endoplasmic protein Nogo-B (RTN4-B) interacts with GRAMD4 and regulates TLR9-mediated innate immune responses. J Immunol. 2015;194:5426-36.

35. Takeda K, Kaisho T, Akira S. Toll-like receptors. Annu Rev Immunol. 2003;21: 335-76.

36. Tian J, Avalos AM, Mao SY, Chen B, Senthil K, Wu H, et al. Toll-like receptor 9-dependent activation by DNA-containing immune complexes is mediated by HMGB1 and RAGE. Nat Immunol. 2007;8:487-96.

37. Yanai H, Ban T, Wang Z, Choi MK, Kawamura T, Negishi H, et al. HMGB proteins function as universal sentinels for nucleic-acid-mediated innate immune responses. Nature. 2009;462:99-103.

38. Sirois CM, Jin T, Miller AL, Bertheloot D, Nakamura H, Horvath GL, et al. RAGE is a nucleic acid receptor that promotes inflammatory responses to DNA. J Exp Med. 2013;210:2447-63.

Key Words: ischemia/reperfusion, HMGB1, cell-free DNA, RAGE, TLR9, spleen 


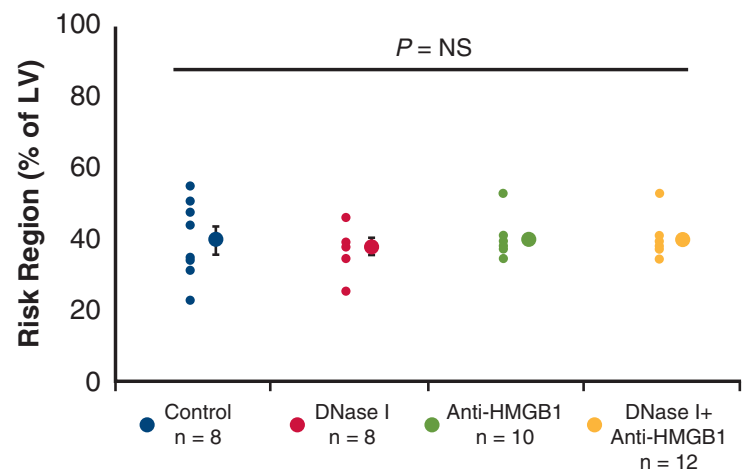

FIGURE E1. Risk regions were similar among all groups. $L V$, Left ventricle; NS, not significant; DNase I, deoxyribonuclease I; anti$H M G B 1$, anti-high-mobility group box 1 .

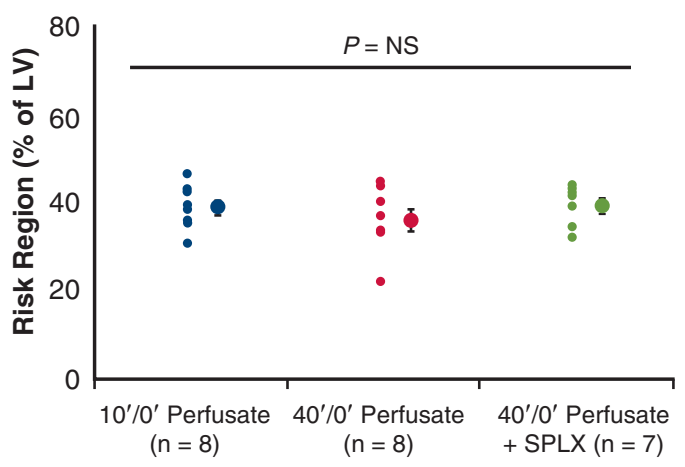

FIGURE E2. Risk regions were similar among all groups. $L V$, Left ventricle; $N S$, not significant; $S P L X$, splenectomy. 


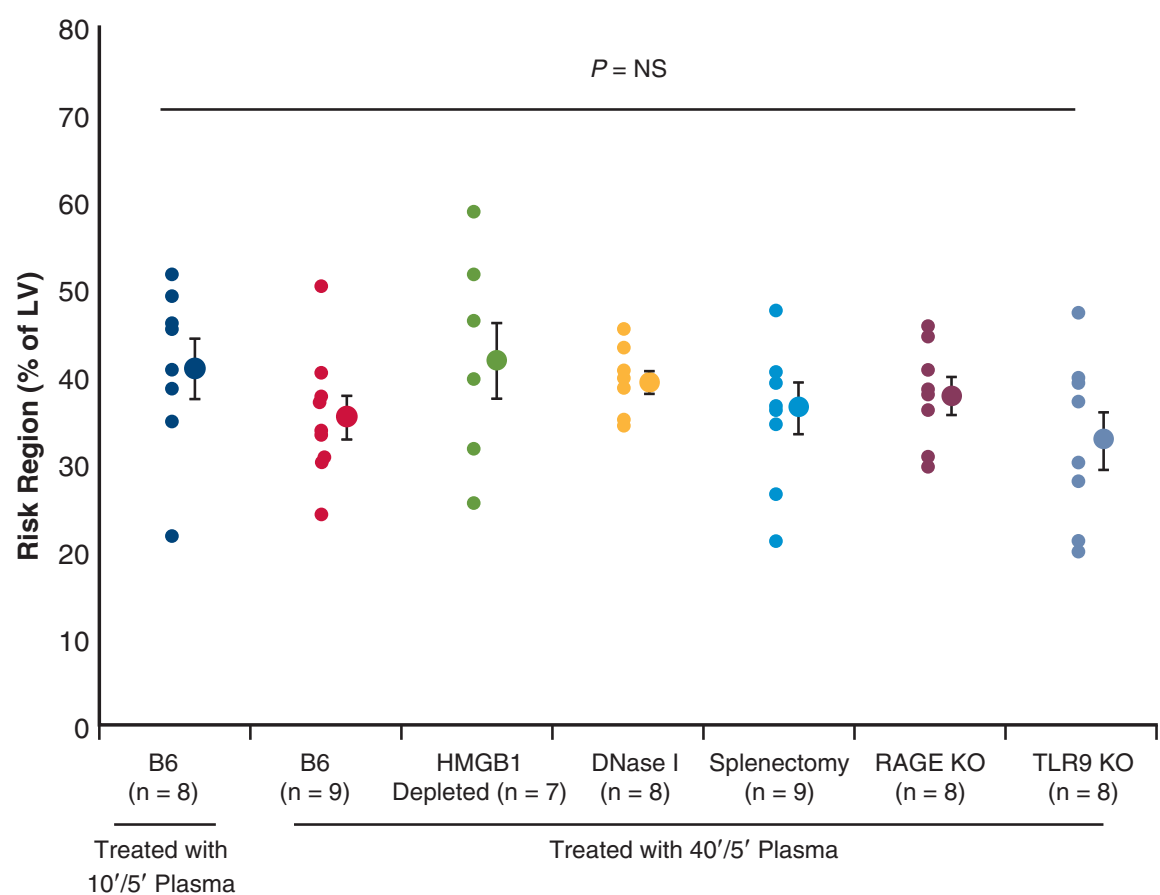

FIGURE E3. Risk regions were similar among all groups. $L V$, Left ventricle; $N S$, not significant; $B 6$, C57BL/6; $H M G B 1$, high-mobility group box 1; DNase I, deoxyribonuclease I; RAGE KO, receptor for advanced glycation end products knockout; TLR9 KO, Toll-like receptor 9 knockout.

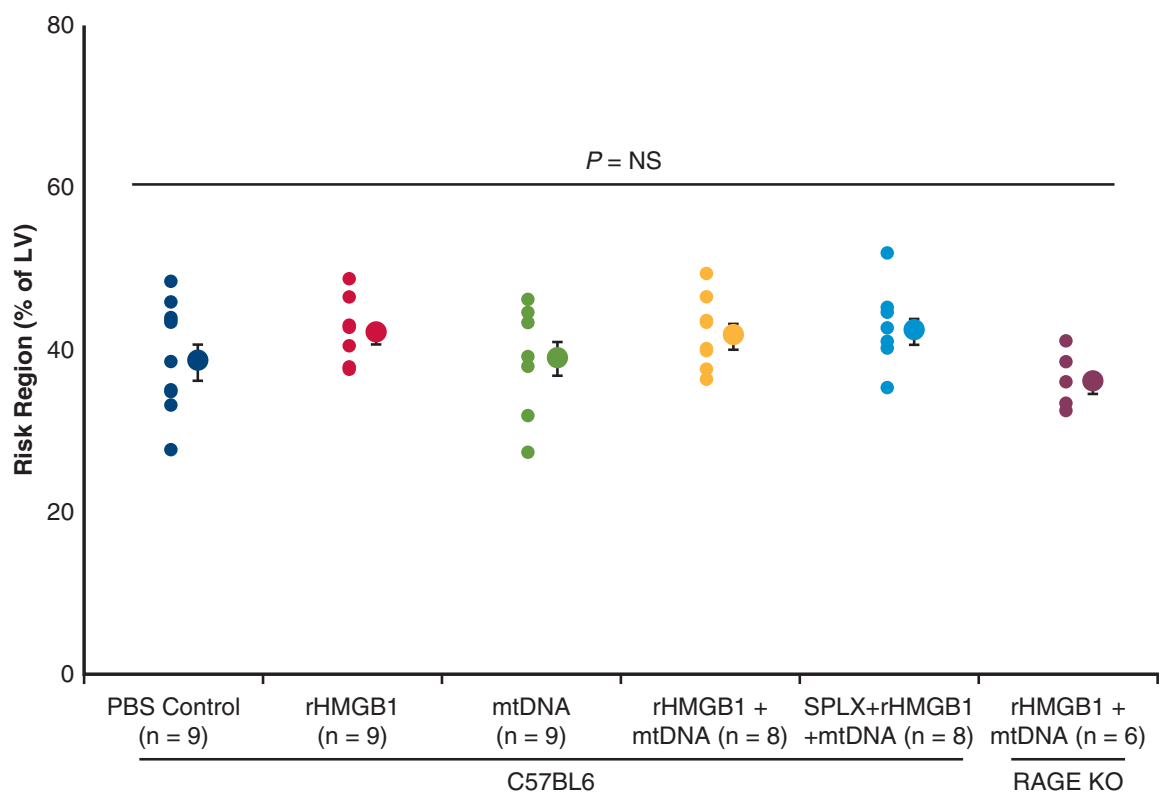

FIGURE E4. Risk regions were similar among all groups. $L V$, Left ventricle; $N S$, not significant; $P B S$, phosphate buffered saline; $r H M G B 1$, recombinant high-mobility group box 1; mtDNA, mitochondrial DNA; SPLX, splenectomy; $R A G E K O$, receptor for advanced glycation end products knockout. 

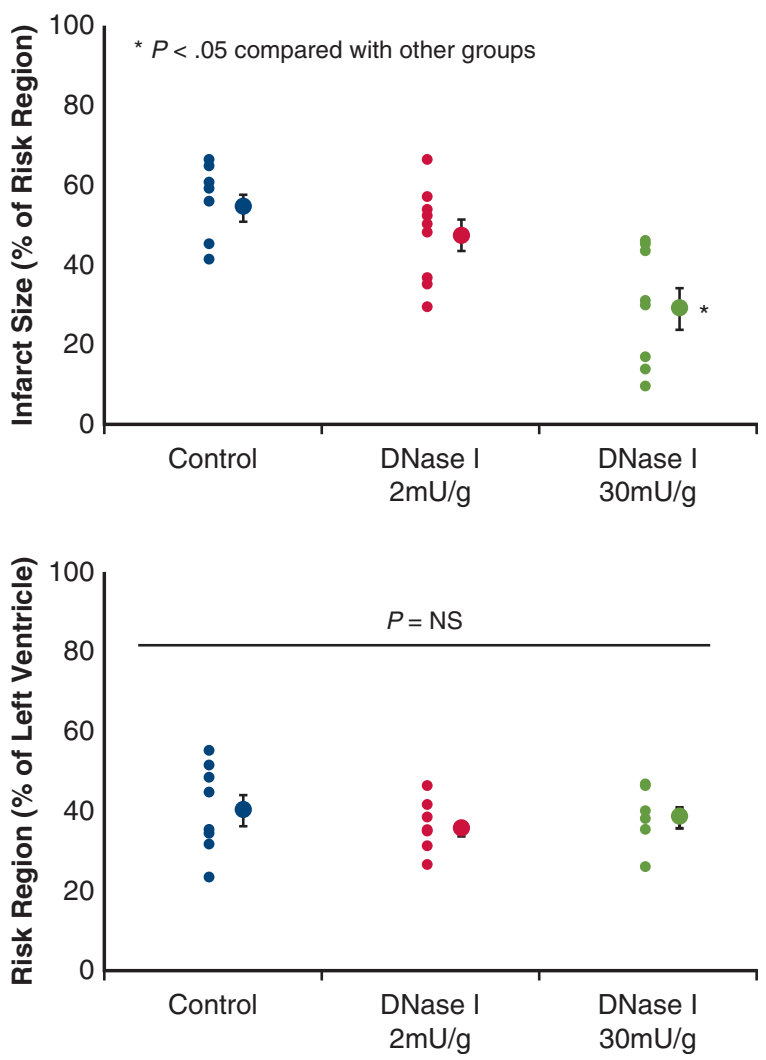

FIGURE E5. Intravenous injection of deoxyribonuclease I (DNase I) at $30 \mathrm{mU} / \mathrm{g}$ reduced myocardial infarct size after $40^{\prime} / 60^{\prime}$ ischemia/reperfusion. Lower dose of DNase I ( $2 \mathrm{mU} / \mathrm{g})$ had no infarct-sparing effect. $N S$, not significant.

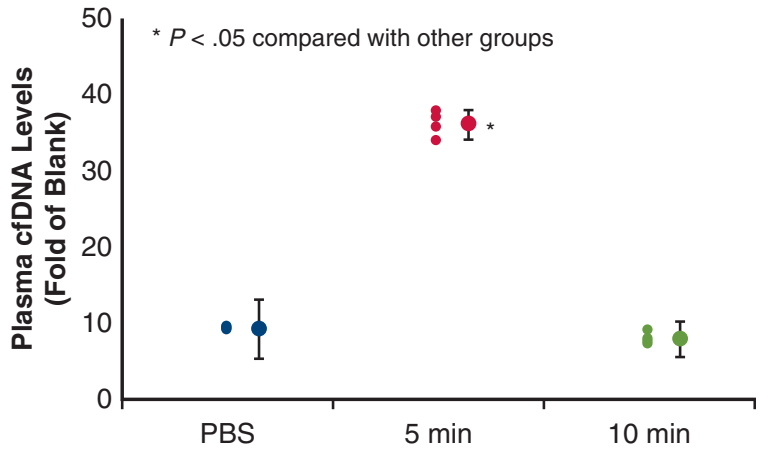

FIGURE E6. Plasma cell-free DNA ( $c f D N A)$ significantly increased after exogenous mitrochondrial DNA injection $(0.5 \mu \mathrm{g} / \mathrm{g})$ at 5 minutes. At $30 \mathrm{mi}-$ nutes, plasma cfDNA decreased back to the normal level. PBS, Phosphate buffered saline. 